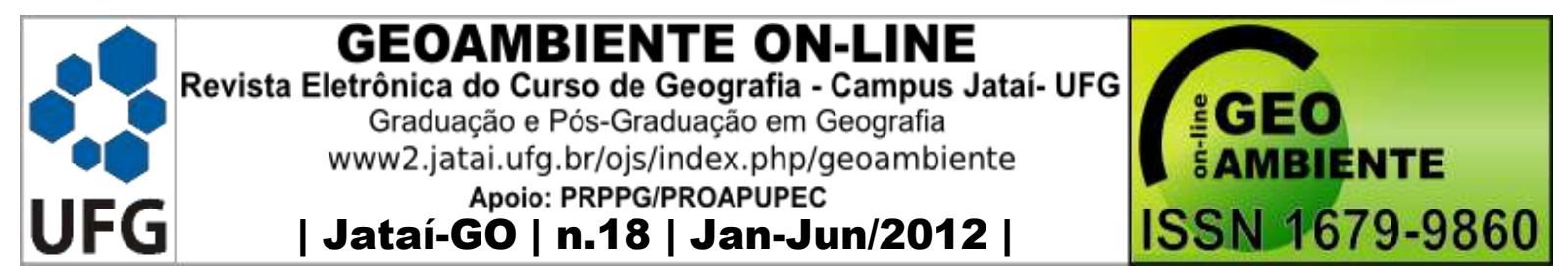

\title{
O USO DE TÉCNICAS DE GEOPROCESSAMENTO E GEOESTATÍSTICA COMO FERRAMENTA PARA GESTÃo MUNICIPAL
}

Monalisa Cristina Silva Medeiros ${ }^{1}$, Adailton Lima Silva ${ }^{1}$, Janierk Pereira Freitas ${ }^{1}$, João Damasceno Damasceno ${ }^{2}$

( 1 - Universidade Federal de Campina Grande, Mestranda em Recursos Naturais - UFCG, monalisacristinasm@hotmail.com,adailton_limasilva@hotmail.com,janierk_pfreitas@hotmail .com, 2 - Universidade Estadual de Campina Grande,Dr em Ciências Agrárias, jdamasceno_uepb@hotmail.com)

\section{Resumo}

O objetivo deste trabalho é avaliar a dinâmica das condições socioeconômicas e ambientais a partir do estudo de caso do bairro de Bodocongó na cidade de Campina Grande (PB). A metodologia consiste no uso de técnicas de geoestatística e geoprocessamento, a partir da coleta de dados e técnicas computacionais e estatísticas a fim de delimitar sua áreas de fragilidades. Além disso, foi realizado um levantamento bibliográfico, pesquisa in loco com aplicação de questionários, juntamente com técnicas de geoestatisca e geopocessamento. Como resultados d pesquisa foi possível identificar que a área de estudo é carente de políticas públicas, onde se faz necessário uma maior atenção por parte dos gestores para que a população tenha uma melhor qualidade de vida, tendo em vistas os diversos problemas identificados na infraestrutura do bairro que reflete na população. Assim, esta abordagem de trabalho permite, além da identificação dos mais diversos problemas, a proposição de subsídios para um melhor planejamento urbano.

Palavras Chave: Condições socioeconômicas, meio ambiente, gestão municipal.

\section{Abstract \\ USING GIS AND GEOSTATISTICAL TECHNIQUES AS A TOOL FOR MUNICIPAL MANAGEMENT}

\footnotetext{
Artigo recebido para publicação em 07 de Dezembro de 2011

Artigo aprovado para publicação em 05 de Abril de 2012
} 


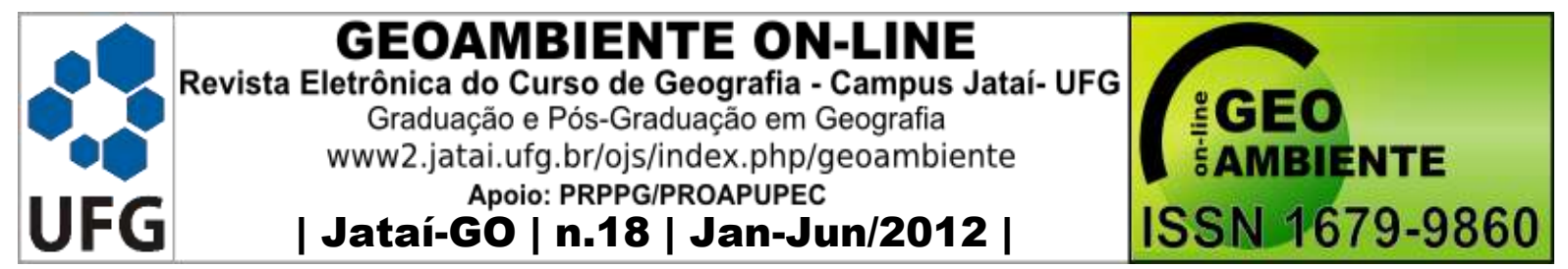

The objective of this study is to assess the dynamics of socioeconomic and environmental conditions from the studied case of Bodocongó in the city of Campina Grande (PB). The methodology involves the use of geostatistical techniques and GIS, from data collection and statistical and computational techniques in order to delimit their areas of weaknesses. In addition, we performed a literature review, investigations in situ applying questionnaires, as well as, with geostatistical and geoprocessing techniques. As a result the study was identified that the study area needs more public policy, where there is a need for greater attention from managers for the population to have a better quality of life, having seen the various problems identified in the infrastructure neighborhood that reflects the population. Thus, this approach allows work in addition to the identification of various problems, proposing subsidies for better urban planning.

Keywords: Socioeconomic, environmental, municipal management.

\section{Resumen}

\section{EL USO DE GEOPROCESAMIENTO TÉCNICAS Y MANEJO DE LA GEOESTADÍSTICA COMO HERRAMIENTA PARA LA MUNICIPAL}

El objetivo de este estudio es evaluar la dinámica de las condiciones socioeconómicas y ambientales del barrio caso Bodocongó estudio en la ciudad de Campina Grande (PB). La metodología implica el uso de técnicas geoestadísticas y los SIG, desde la recogida de datos y técnicas estadísticas y computacionales con el fin de delimitar sus áreas de debilidad. Además, se realizó una revisión de la literatura, lugar de la encuesta con cuestionario, junto con las técnicas y geopocessamento geoestatisca. Como resultado de un estudio d se identificó que el área de estudio es una política pública pobre, donde hay una necesidad de una mayor atención por parte de los administradores para que la población tenga una mejor calidad de vida, después de haber visto los diversos problemas detectados en la infraestructura barrio que refleja la población. Por lo tanto, este enfoque permite que el trabajo, además de la identificación de varios problemas, proponer las subvenciones para una mejor planificación urbana.

Palabras clave: socioeconómico, la gestión ambiental, municipal.

\section{INTRODUÇÃO}




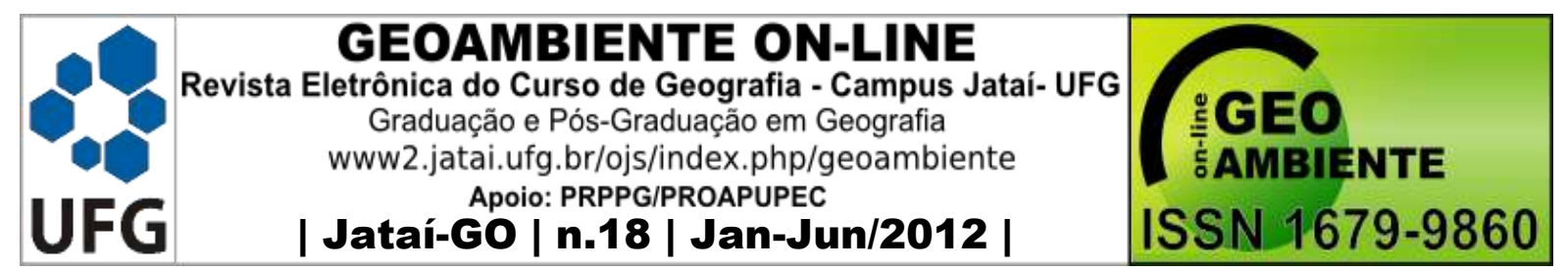

A evolução tecnológica vivenciada nos últimos anos tem proporcionado avanços em todas as áreas do conhecimento científico, e na geografia isso não tem sido diferente, tendo como um importante instrumento o geoprocessamento e a geoestatistica, que foi aprimorado na década de 1970 com a geografia quantitativa, proporcionando maiores contribuições e analises espaciais mais eficazes e eficientes. O geoprocessamento utiliza técnicas matemáticas e computacionais para o tratamento da informação geográfica, com instrumentos e softwares diversificados.

Os campos de aplicação são bastante diversificados devido às suas potencialidades, sendo ultilizados amplamente em estudos ecológicos, estudos de impacto ambiental, dentre outros. E sobretudo na produção de mapas, suporte para análise espacial e como um banco de dados geográficos, disponibilizando informações georreferenciadas sobre um território a fim de um melhor entendimento dos seus fenômenos. Dentre os setores que utilizam esta importante ferramenta, pode-se destacar a Gestão Municipal, tendo em vista que é imprescindível o conhecimento do território para tomadas de decisões e planejamento urbano. Desta maneira, informações subsidiadas por técnicas de geoprocessamento e geoestatistica, apresentam melhor suporte e segurança para tomadas de decisões.

Pode-se evidenciar que a maioria dos problemas enfrentados nas cidades ocorre devido a falta de um planejamento adequado. A maioria da população brasileira mora em cidades, e na maioria das vezes o processo de urbanização não ocorre com um planejamento adequado, isso porque, segundo Suchs (2006), a realidade urbana acaba sendo tratada e conduzida pelo setor estatal por uma ótica privatista, ou seja, busca-se um planejamento e uma preocupação para empreendimentos de lotes privados, deixando de lado desta forma, os espaços convenientes para toda população, e não apenas para uma parte que reside em lotes privados.

$\mathrm{O}$ crescimento das cidades tem sido uma constante, e acaba exigindo que os gestores cada vez mais ampliem seus conhecimentos com um maior numero de informações possíveis para facilitar a gestão do território. Neste sentido, é importante o uso de técnicas que permitam uma melhor visualização do território, tendo em vista que esta ferramenta auxilia os gestores nas tomadas de decisões.

A partir disso, o objetivo geral deste trabalho é analisar as condições ambientais de um recorte do bairro de Bodocongó na cidade de Campina Grande (PB), com uso de técnicas de geoestatística e geoprocessamento, e como específicos: avaliar a dinâmica ambiental a 


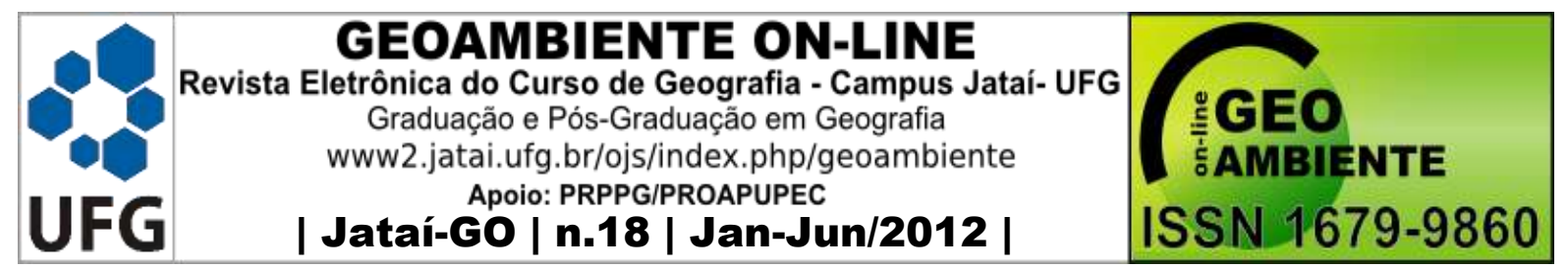

partir de coleta de dados e técnicas computacionais como forma de modelo de planejamento urbano; e identificar as fragilidades ambientais de um bairro pela representação estatística, procurando delimitar áreas de fragilidades ambientais de modo a subsidiar políticas publicas pertinentes ao local.

\section{MATERIAL E MÉTODOS}

Inicialmente foi realizado um levantamento e análise bibliográfica para um suporte no embasamento teórico e um entendimento mais aprofundado sobre o tema, buscando compreender como o Geoprocessamento e a Geoestatística podem contribuir no planejamento urbano. Para atingir os objetivos, foi realizada estudos do tipo descritivo-análitico, com abordagens quantitativas e qualitativas. $\mathrm{O}$ universo de análise considerado foi um recorte do bairro de Bodocongó, zona oeste do município de Campina Grande PB, definida como área piloto para execução deste trabalho. Realizado um primeiro levantamento in loco, visando delimitação do espaço e contato sobre a realidade local, além da delimitação do universo a ser abordado. A área de estudo delimitada envolveu 6 ruas do bairro (R. Vicente Gomes de Almeida; R. Noberto Teixeira de Brito; R. Herman Levy de Albuquerque Sobrinho; R. Luiz Mota; R. Rubens Dutra Segundo) com um universo de 107 residências, onde esta área apesar de fazer parte do bairro de Bodocongó, é mais conhecido pela população como Ramadinha II.

Os critérios utilizados para nortear a delimitação, formam as condições ambientais das ruas e infraestrutura. Em seguida foi realizada a elaboração de um questionário ambiental para compreender a realidade local. De posse destas informações e tabulados os dados remetendo-os para a aplicação de recursos de geoprocessamento nesta análise urbana, sendo composta pelo uso de aplicativo de gestão e estudo de caso, com utilização do Sistema Geográfico de Informação para ampla análise do recorte espacial enfocado, com integração dos estudos de planejamento e Gestão Municipal.

Em um primeiro momento foi realizado uma aplicação de questionário teste aleatório, para observar seu comportamento e após a avaliação de um cientista social, para possíveis mudanças ou melhorias nos questionários. Realizado esta etapa, os questionários foram aplicados e, por conseguinte todos os dados foram tabulados para todas as análises pertinentes, seguindo os parâmetros do IBGE.

Para aplicação do questionário, foram delimitadas 50 casas, ordenadas aleatoriamente. Os dados foram coletados no período de Julho de 2011 à setembro de 2011. 


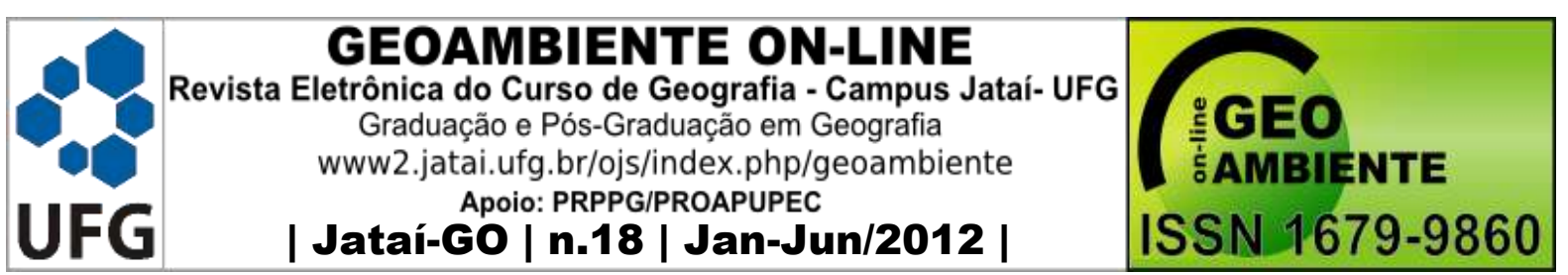

Através da aplicação de questionários diretos as pessoas visitadas, foram compreendidas a distâncias entre os universos de educação, emprego, e padrão de consumo em função das rendas de cada família.

O georeferenciamento da área em estudo foi realizado utilizando a carta digitalizada do município de Campina Grande, do bairro Bodocongó, na escala:1:8.000 , pelo Sistema de Coordenadas Geográfica, com o Datum: SAD 69, realizado pela coordenadoria de planejamento urbano, em Janeiro 2008, e tendo como software manipulador plataforma ArcGIS e SPRING para construção das representações espaciais.

\subsection{Recorte geoestatistico do bairro de Bodocongó}

O bairro de Bodocongó (Figura 1) está localizado na cidade de Campina Grande (PB) que faz divisa ao Norte com os municípios Lagoa Seca, Massaranduba, Pocinhos e Puxinanã; ao Sul com Boqueirão, Caturité, Fagundes e Queimadas; ao Leste com Riachão do Bocamarte; e a Oeste com Boa Vista e está a 130 Km da capital João Pessoa.

Figura 1 - Mapa de localização do bairro de Bodocongó, Campina Grande-PB.

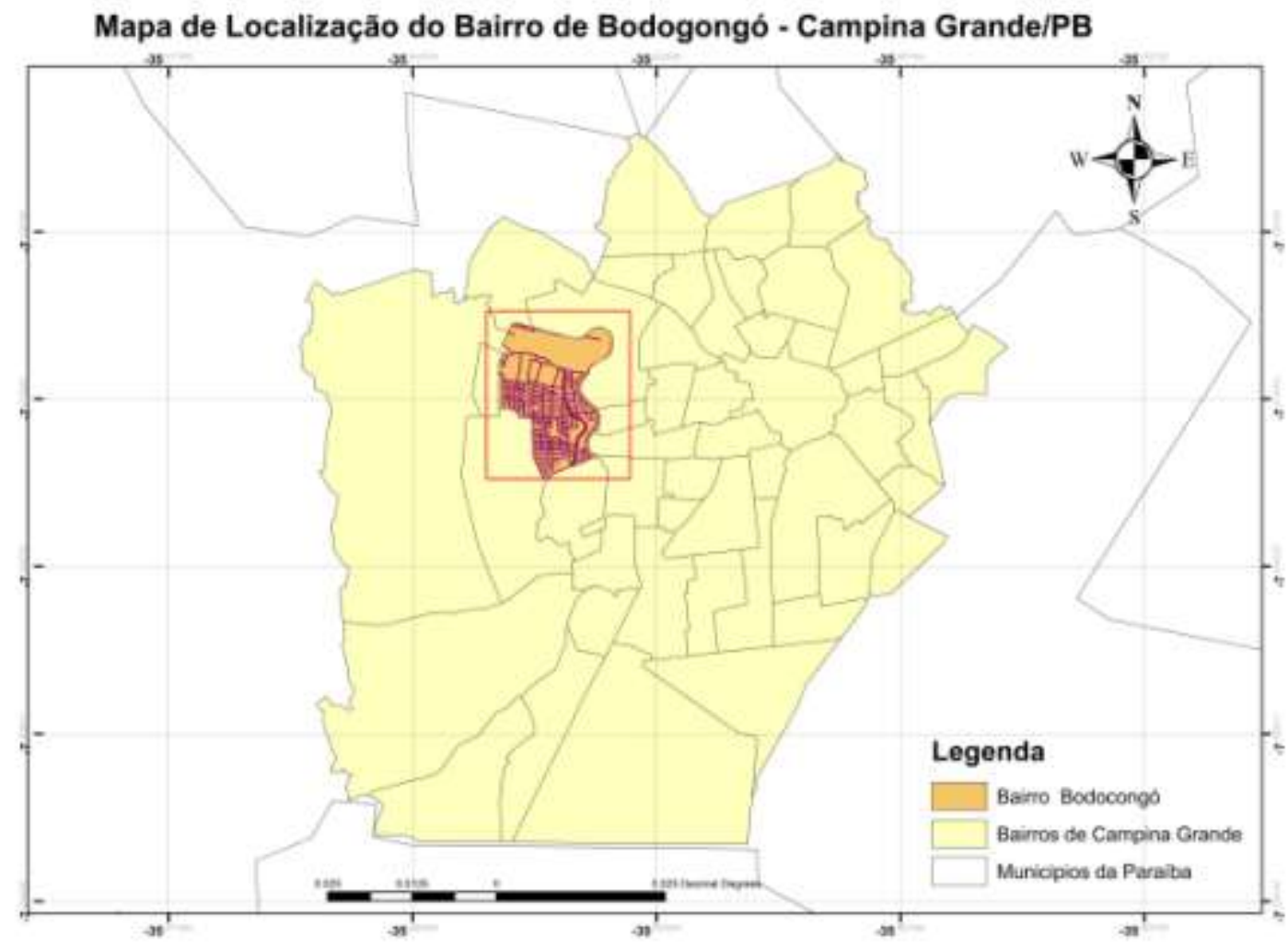




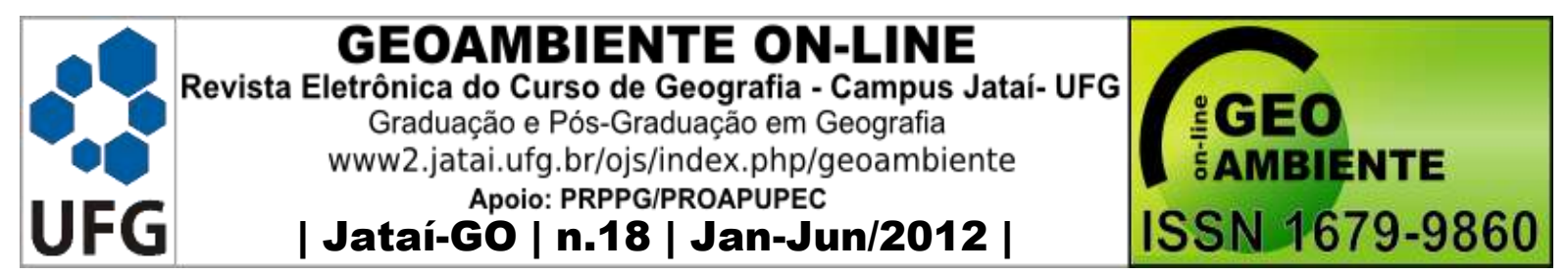

O bairro é uma área carente de políticas públicas, onde se faz necessário uma maior atenção por parte dos gestores para esta população que carece de melhorias na infraestrutura urbana desta localidade, como saneamento básico adequado, ruas devidamente calçadas, segurança etc. No entanto é importante ressaltar os contrastes sociais existentes no próprio bairro, isso porque, de um lado encontra-se uma parte da população que detém um poder aquisitivo maior, e dispõem de uma melhor infra estrutura, com ruas calçadas, saneamento básico, coleta regular de resíduos sólidos, segurança, etc. Outra porção do bairro, que consiste na área pesquisada, existe uma população que além de carente, não disponibiliza de uma infra estrutura adequada, criando assim espaços segregados. Diante disso, nossa atenção voltou-se para esta área, em virtude da sua fragilidade social, econômica e ambiental, procurando então delimitar estes espaços, buscando analisar a dinâmica sócio espacial a partir da qualidade de vida e ambiental desta população.

Diante disso, buscou-se a compreensão desta dinâmica a partir de um recorte do bairro de Bodocongó com a delimitação de 6 ruas, possuindo um universo de 107 casas, onde a coleta de dados com a aplicação de questionários sócio econômico e ambiental, ocorreu em 50 casas, ordenadas aleatoriamente. A análise descritiva dos dados apresenta como principal ideia trabalhar com estatísticas tendo como objetivo obter um cenário da realidade. Neste sentindo, buscou-se extrair dos dados a maior quantidade possível de informação, que auxilie no tratamento destes dados a serem usados para poder delimitar um melhor planejamento.

\section{RESULTADOS E DISCUSSÕES}

\subsection{Análise sócio econômica}

A partir dos dados coletados, podemos fazer diversas analises sócio econômico da população do bairro de Bodocongó através de vários indicadores. As estatísticas apresentadas a seguir possibilitam captar características sociais e econômicas da população residente, permitindo conhecer e avaliar as condições de vida de seus moradores bem como seu perfil.

As informações obtidas através da aplicação de questionários evidenciaram a faixa etária da população, origem das pessoas que compõem a população, o tempo de residência na comunidade, a quantidade média de habitantes por casa, ocupação dos responsáveis pelo domicilio, renda mensal, auxilio de ajuda externa, grau de escolaridade e moradia. Os resultados da pesquisa representam a opinião dos moradores do bairro que foram entrevistados. 


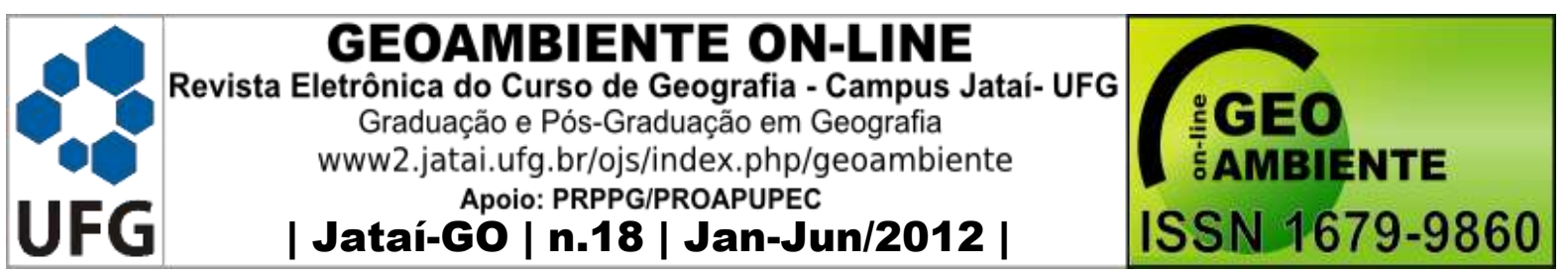

\subsubsection{Faixa etária da população do bairro}

Um componente importante na formação de uma comunidade é a faixa etária (Figura 2), pois através dela pode-se definir o perfil sócio-econômico da mesma, sendo fundamental na construção do meio ambiente, além de definir se há possibilidade de transformação de uma sociedade (BARRETO et al, 2008 p. 9).

O bairro apresenta uma população relativamente jovem, como pode ser observado, nota-se que a idade predominante da população é entre 20 (vinte) a 60 (sessenta) anos, evidenciando uma faixa etária economicamente ativa, com expectativa de melhoria da qualidade de vida. Em sua maioria apresenta união estável (Figura 3), o que vem a refletir em famílias estruturadas. Isso pôde ser confirmado com a variável que indica o total de residentes, onde constata-se que em $64 \%$ dos domicílios residem de 4 a 7 pessoas, compostos por conjugues, filhos e/ou parentes (em algumas residências).

Figura 2 - Faixa Etária da população

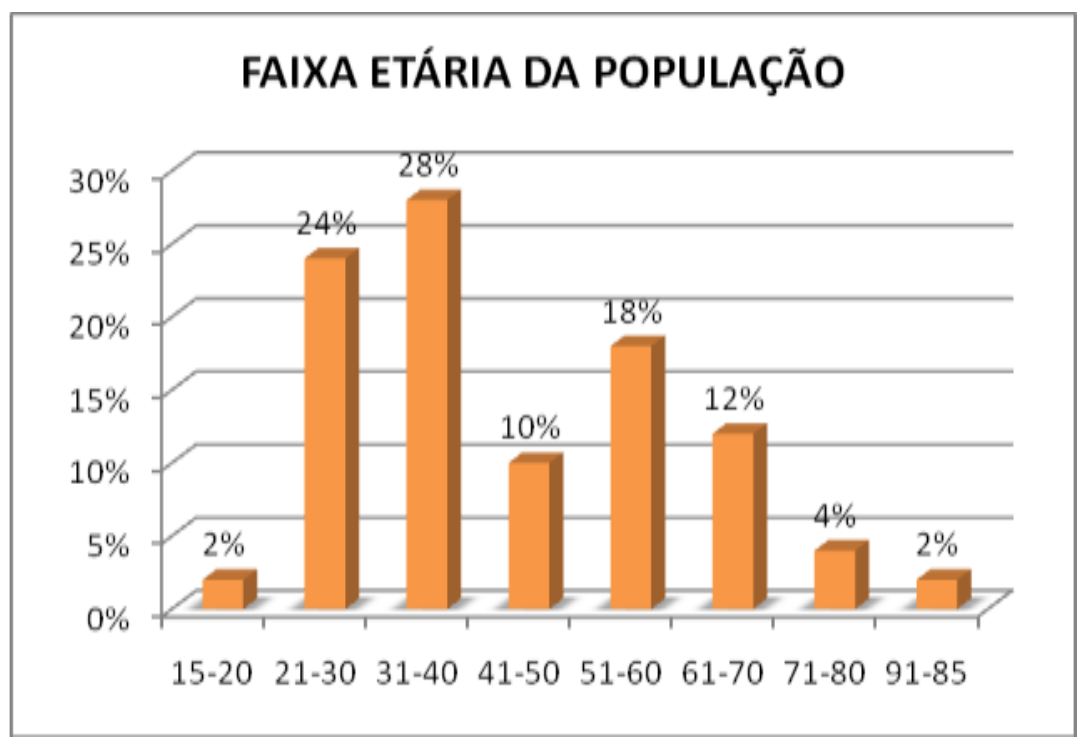

Fonte: Pesquisa de Campo - MEDEIROS, Monalisa Cristina Silva. 2011. 
Figura 3 - Estado civil da população

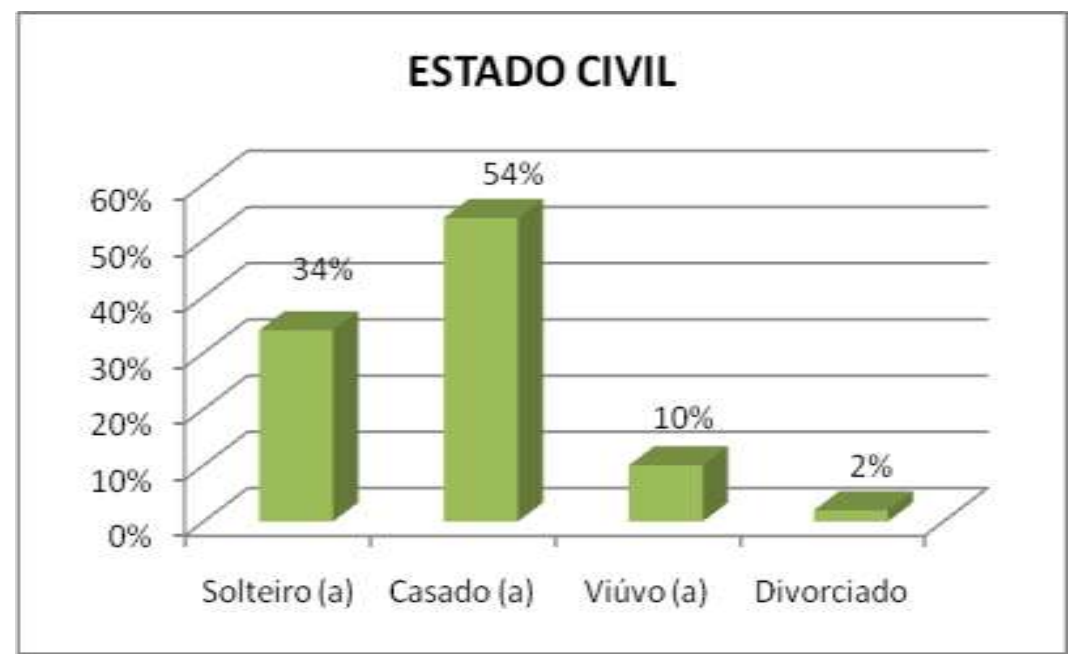

Fonte: Pesquisa de Campo - MEDEIROS, Monalisa Cristina Silva. 2011.

\subsubsection{Cidade de Origem}

A Figura 4 demonstra que a maioria da população entrevistada é natural da própria cidade, Campina Grande com $64 \%$ dos entrevistados, enquanto os demais em sua maioria são naturais de cidades próximas a Campina Grande; Areial, Patos, Alagoa Nova, Souza, Ingá, Lagoa Seca, Cuité, Puxinanã, Cubati, São Sebastião de Lagoa de Roça, Massaranduba, apresentando um percentual de $2 \%$ cada, e ainda de outros estados como Rio Grande do Norte, Pernambuco e São Paulo com o mesmo percentual cada um. Os entrevistados escolheram o bairro como local de moradia por motivos múltiplos.

Figura 4 - Naturalidade da população

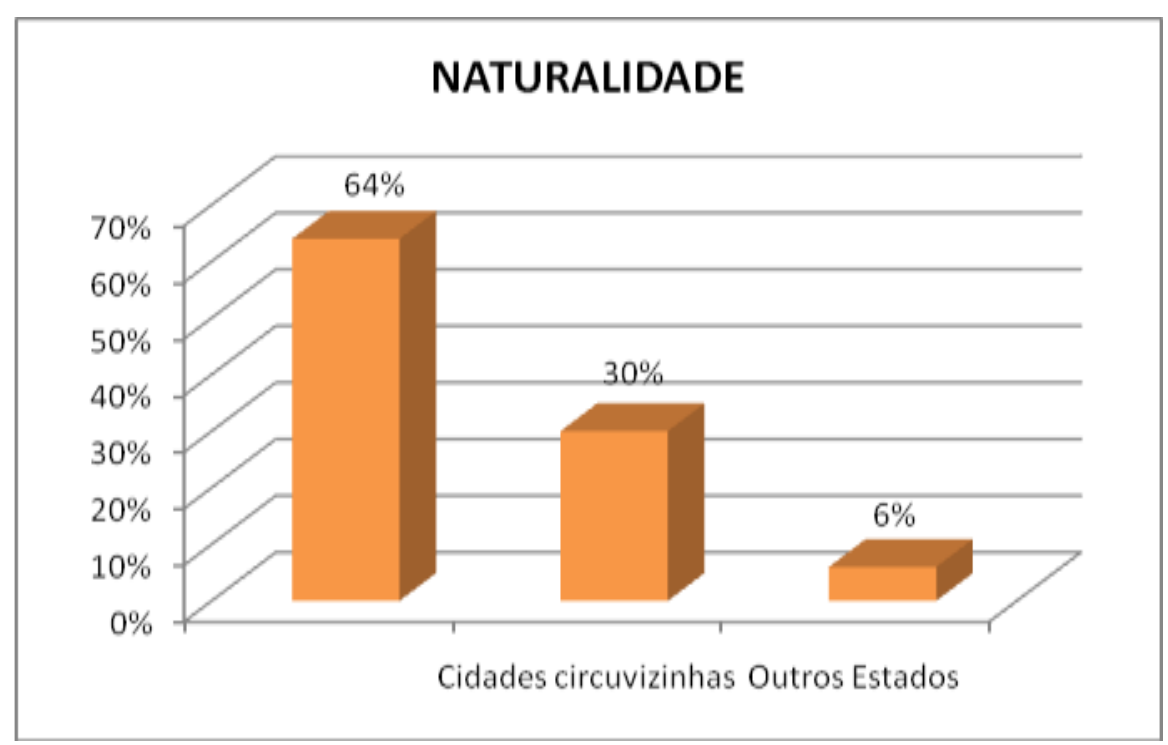

Fonte: Pesquisa de Campo - MEDEIROS, Monalisa Cristina Silva. 2011. 


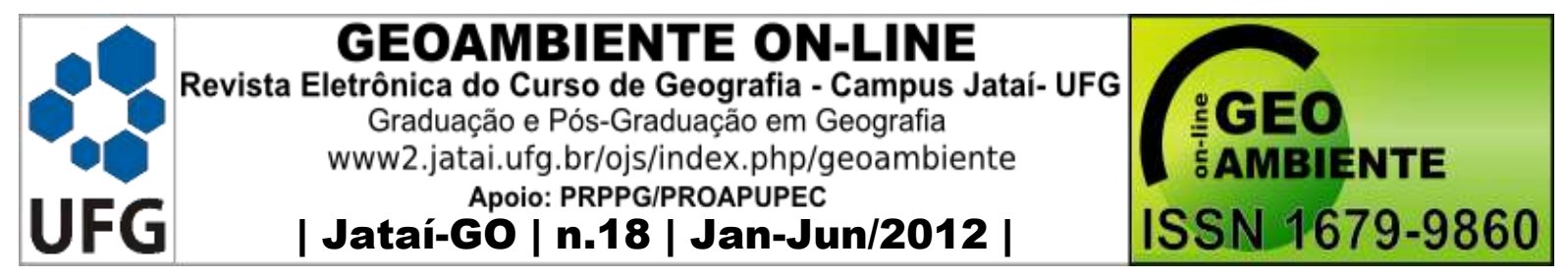

Os moradores mais antigos, em virtude das indústrias que existiam em sua proximidade, além de famílias que após a união dos conjugues vieram residir no bairro fixando residência neste local a vários anos. Já os mais recentes revelam que alguns residem por falta de opção e outros devido à possibilidade de aluguel residencial com menor custo financeiro.

\subsubsection{Tempo de Moradia da população no bairro}

De acordo com Barreto et al (2008 p.10), esta variável é importante para determinar a relação dos entrevistados com o bairro (vantagens e desvantagens da moradia, relacionamento interpessoal, atuação do poder público, etc), visto que quanto mais antiga uma comunidade, mais riqueza possui nos detalhes de sua história. O tempo de residência da população varia, com uma porcentagem que releva que apesar das dificuldades encontradas no bairro uma parcela da população $28 \%$, permanece no local a mais de 15 anos, sendo conhecedores de todas as dificuldades físicas e sociais que o local oferece, como a ausência de infra estrutura, sobretudo saneamento básico. Outra parcela da população que totaliza $32 \%$ da mesma é relativamente jovem, por fixarem residência a poucos anos, não ultrapassando 5 anos (Figura 5).

Figura 5 - Tempo de Moradia da população no bairro

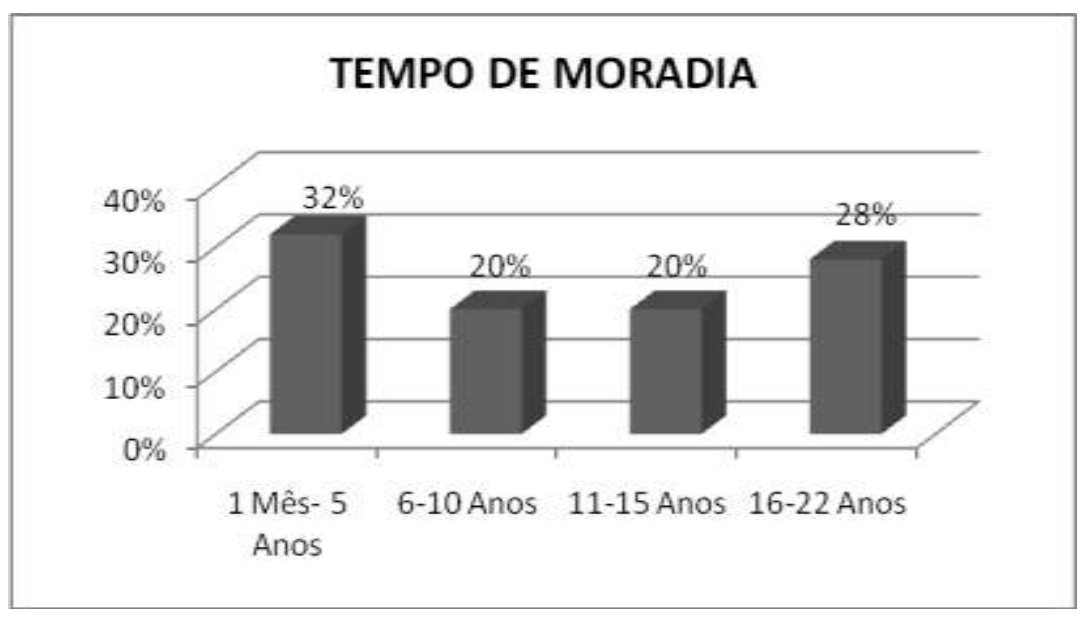

Fonte: Pesquisa de Campo - MEDEIROS, Monalisa Cristina Silva. 2011.

Diante disso, verifica-se que existe uma dinâmica populacional intensa, e que merece maior atenção quantos aos serviços e equipamentos urbanos. 


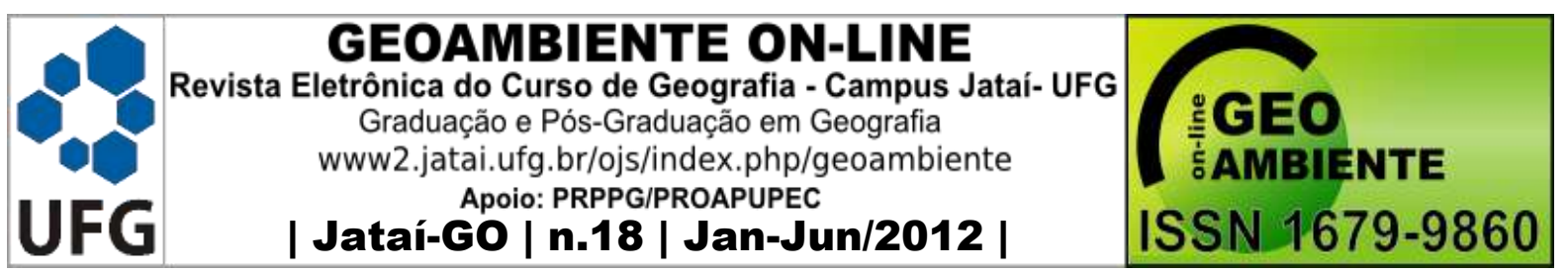

Esta é uma importante variável para avaliar o comportamento de uma população, pois através do domínio do conhecimento, o indivíduo se torna mais crítico e passa a exercer de maneira mais adequada seu papel de cidadão (BARRETO et al 2008 p. 9). No bairro existe um baixo nível de escolaridade, onde uma parcela significativa da população tem apenas o Ensino Fundamental incompleto (Figura 6). Isso reflete na condição e qualidade de vida, tendo em vista que sem um grau de conhecimento, as opções de emprego na maioria das vezes refletem baixos salários, pois segundo Alves, Soares (1996) “[...] a oferta de empregos mudou de qualidade. Pelo menos nos setores mais modernos e dinâmicos, exige-se agora que o trabalhador tenha determinadas habilidades que somente a educação de caráter geral é capaz de preencher" p.7.

Esta realidade aplica-se, sobretudo a população mais velha, enquanto os jovens estudam em escolas publicas. Outro fato importante, é deste percentual, observa-se que não existe pessoas com Ensino Superior completo $(0 \%)$ como pode ser observado no gráfico a seguir, confirmando a baixa escolaridade desta população. As crianças (menores de 7 anos) por sua vez, em sua maioria estudam em escolas particulares do próprio bairro, que muitas vezes não são registradas e funcionam mais como creches do que escolas, e devido a mensalidade ser de baixo custo, as famílias conseguem matricular seus filhos nas mesmas.

Figura 6 - Nível de Escolaridade.

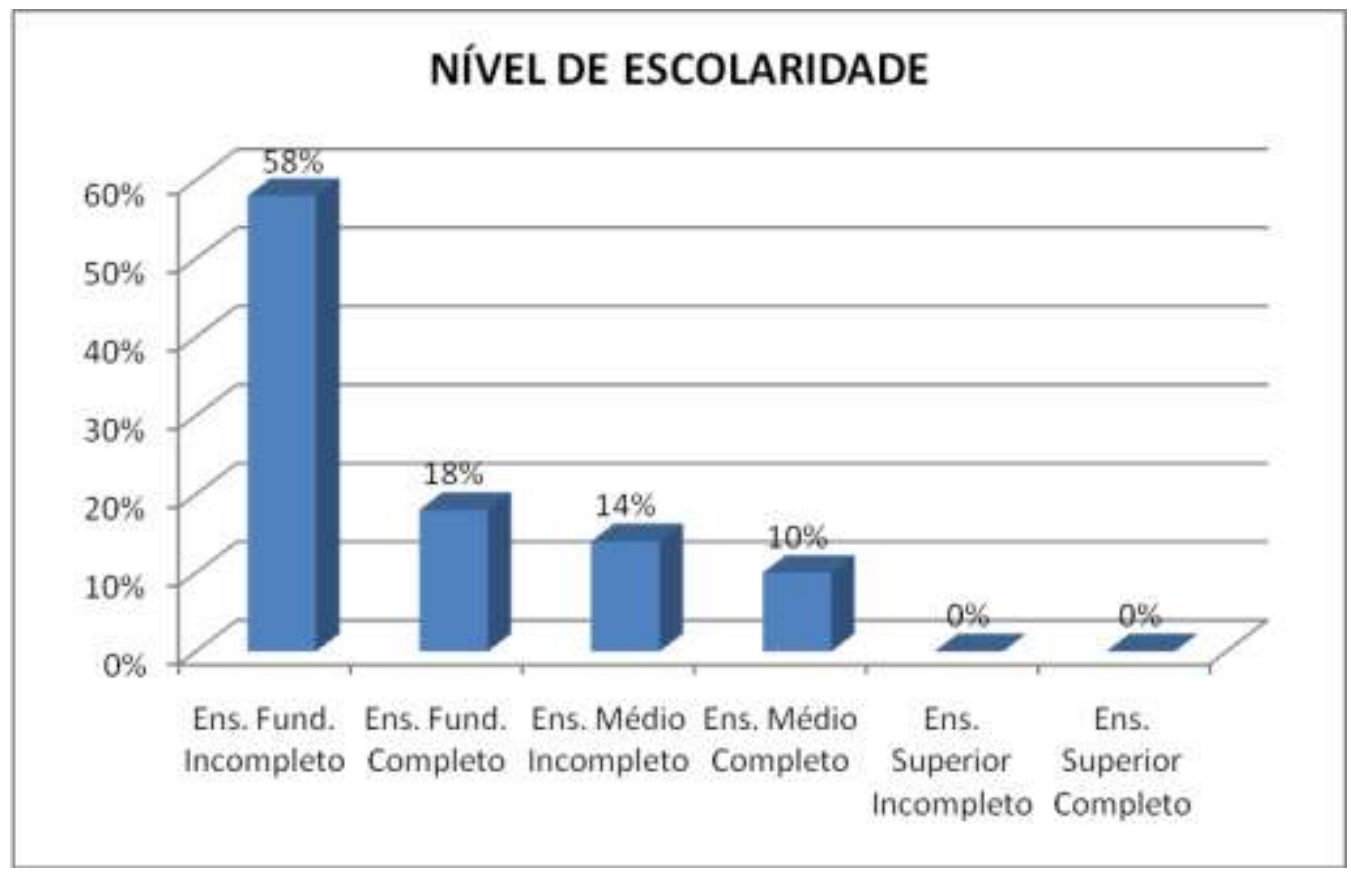

Fonte: Pesquisa de Campo - MEDEIROS, Monalisa Cristina Silva. 2011. 


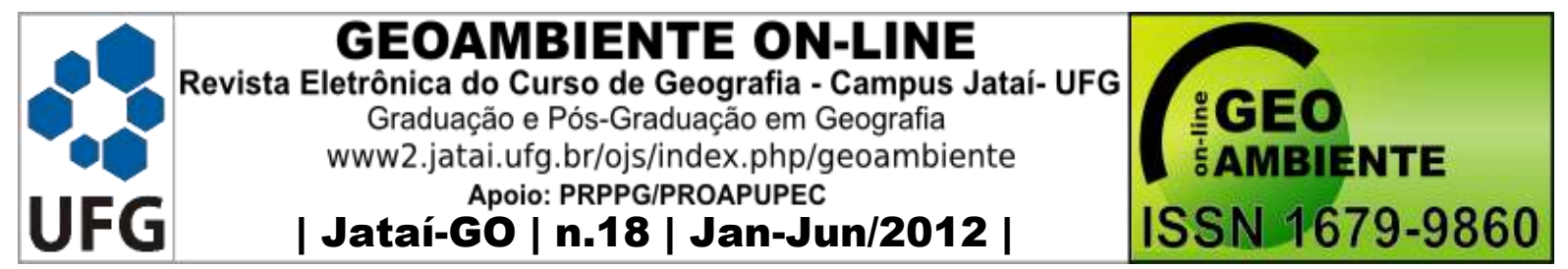

3.1.5 Trabalho (Ocupação)

Este dado é importante para a compreensão de como se comporta a renda mensal da população. Foi observado que na maioria das residências a responsabilidade da renda familiar é de apenas uma pessoa, geralmente o conjugue responsável. Estes apresentam vários tipos de ocupação como: Frentista, Jardineiro, Vendedor de frutas, mecânico, serventes, porteiro, operador de máquinas, auxiliar de limpeza, serviço e produção, diarista, ou seja, todos ligados ao setor terciário.

Existe um índice de $46 \%$ das mulheres que são donas de casas, nestes domicílios o proveniente da renda familiar são seus conjugues, e estas cuidam apenas da casa e dos filhos. Algumas ainda desempenham algum tipo de atividade para complementar a renda em sua própria residência, cerca de 18\%, como; industria caseira (venda de doces e/ou salgados), serviços de representação, comercio de confecções, costura. Ainda existe uma pequena parcela de desempregados $4 \%$, onde a família sobrevive com ajuda de terceiros ou programas sociais (Bolsa Família).

\subsubsection{Renda familiar e ajuda externa}

Esta variável possibilita uma caracterização mais correta das condições econômica e financeira dos entrevistados. O perfil econômico da população do bairro de Bodocongó pode ser considerada como classe media baixa, a renda mensal varia entre um a dois salários mínimos em sua maioria (Figura 7) revelando um baixo poder aquisitivo, tendo em vista que as famílias em sua maioria são compostas pelos conjugues e filhos, e o salário muitas vezes não é suficiente para pagar todas as despesas.

Figura 7 - Renda Mensal.

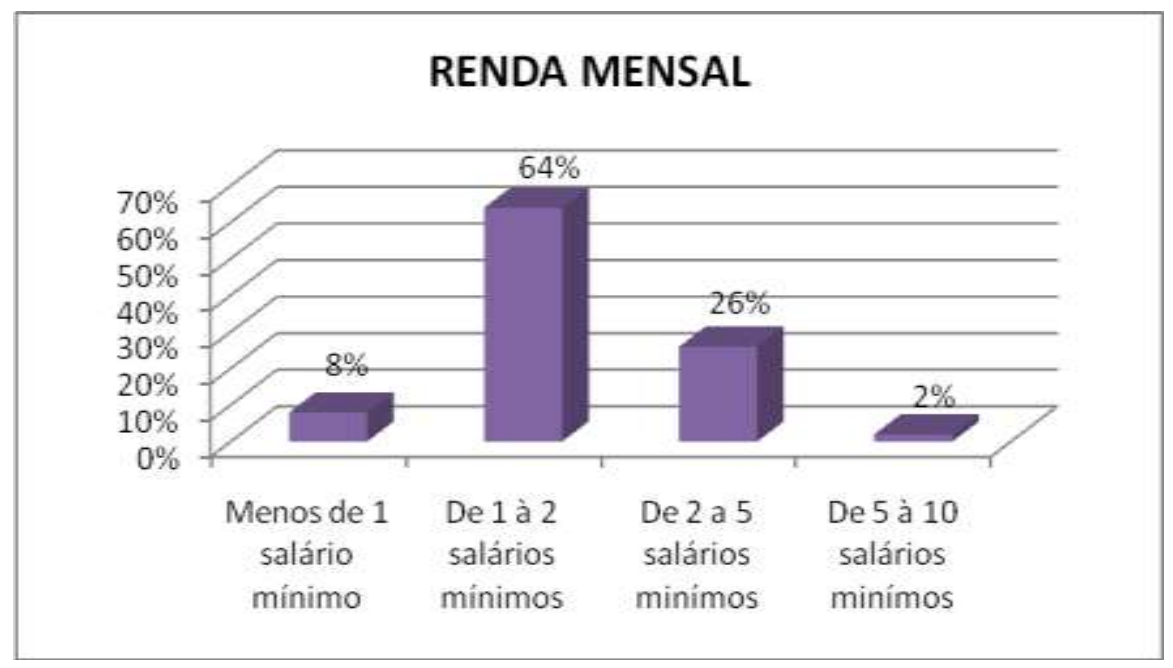




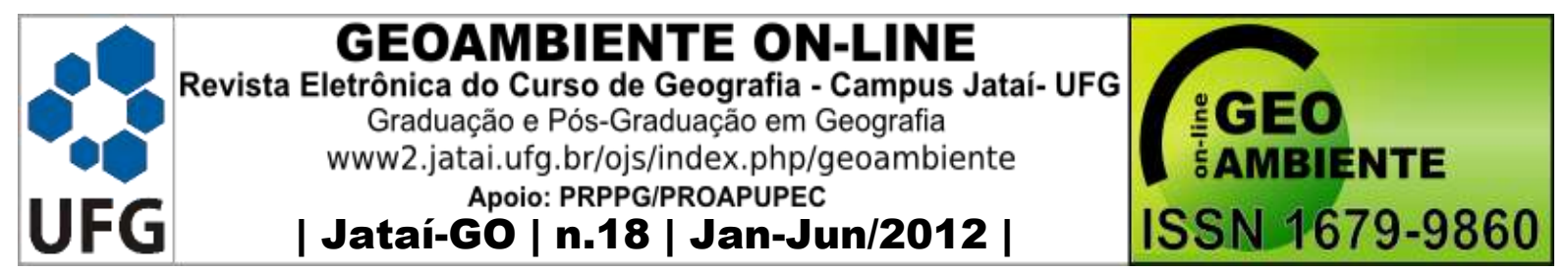

Fonte: Pesquisa de Campo - MEDEIROS, Monalisa Cristina Silva. 2011.

Devido a isto foi identificado, por exemplo, que $90 \%$ da população não possui nenhum tipo de transporte, 96\% fazem uso do Serviço Público de Saúde, enfrentando muitas dificuldades mediante o descaso da saúde que o país enfrenta atualmente. Em sua maioria possuem apenas uma unidade de eletro eletrônicos ou domésticos, como: aparelho de TV, SOM, DVD, Geladeira, Máquina de lavar roupa (76\% não possui), computador. Os próprios moradores afirmam que a renda mensal muitas vezes acaba sendo insuficiente para todas as necessidades, evidenciando assim um baixo poder de consumo.

Ainda foi identificado que as despesas básicas como; conta de luz, conta de água, gastos com transporte público ou privado, remédios e educação, desta população compromete boa parte do rendimento familiar mensal (Figura 8). Tomando como base o salário mínimo atual (510,00 R\$), observa-se que uma parcela considerável desta população do recorte do bairro $(44 \%)$ tem sua renda comprometida em $11-20 \%$, revertida apenas para atender as necessidade básicas. As famílias com menor poder aquisitivo (18\%), com uma renda mensal menor, tem sua renda comprometida para tais fins, de $71-90 \%$, evidenciando desta forma, famílias bastante carentes.

Figura 8 - Perfil Econômico.

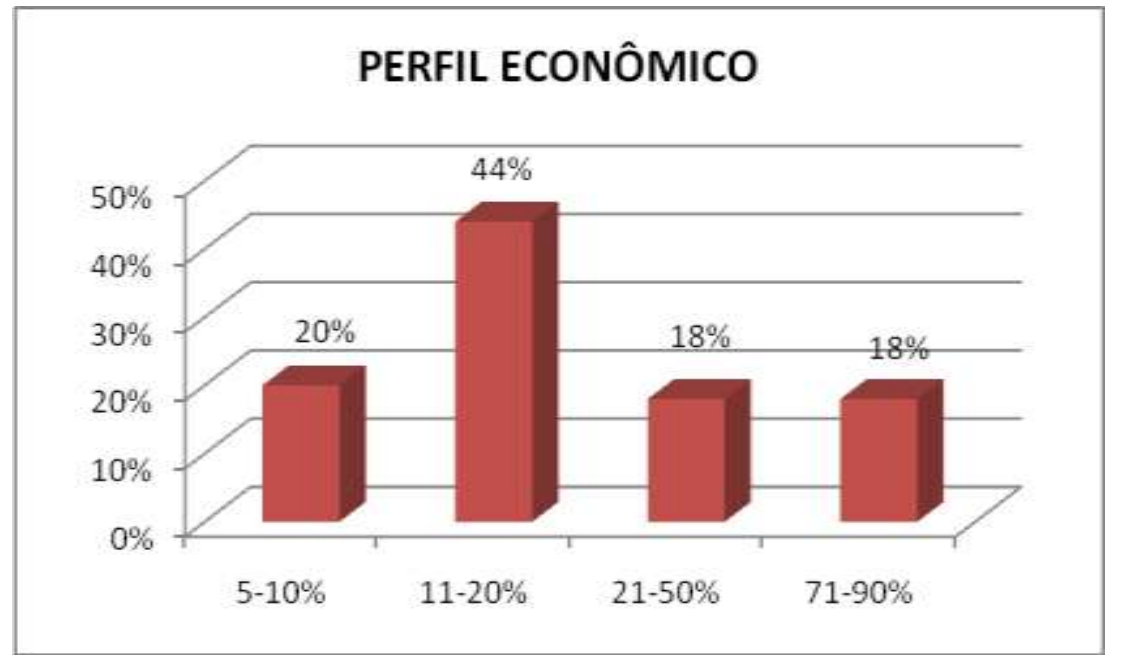

Fonte: Pesquisa de Campo - MEDEIROS, Monalisa Cristina Silva. 2011. 


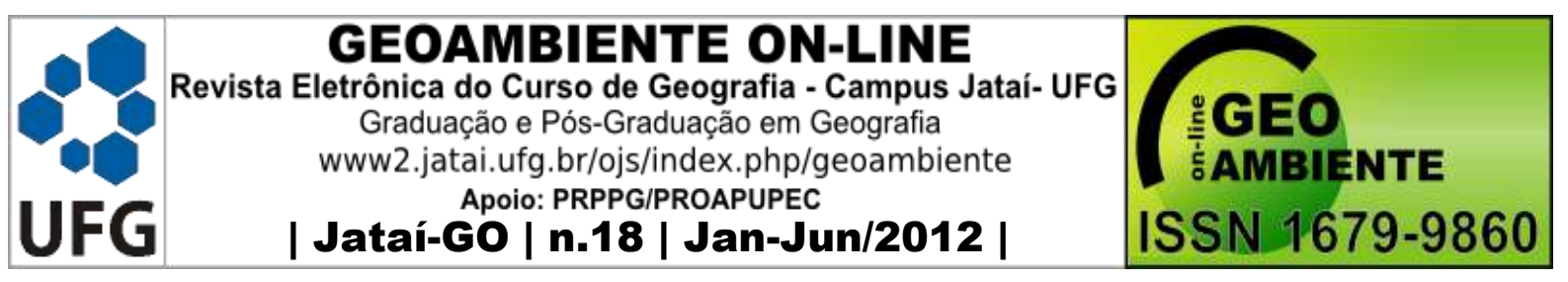

FIGURA 9 - Mapa representando dados econômicos.

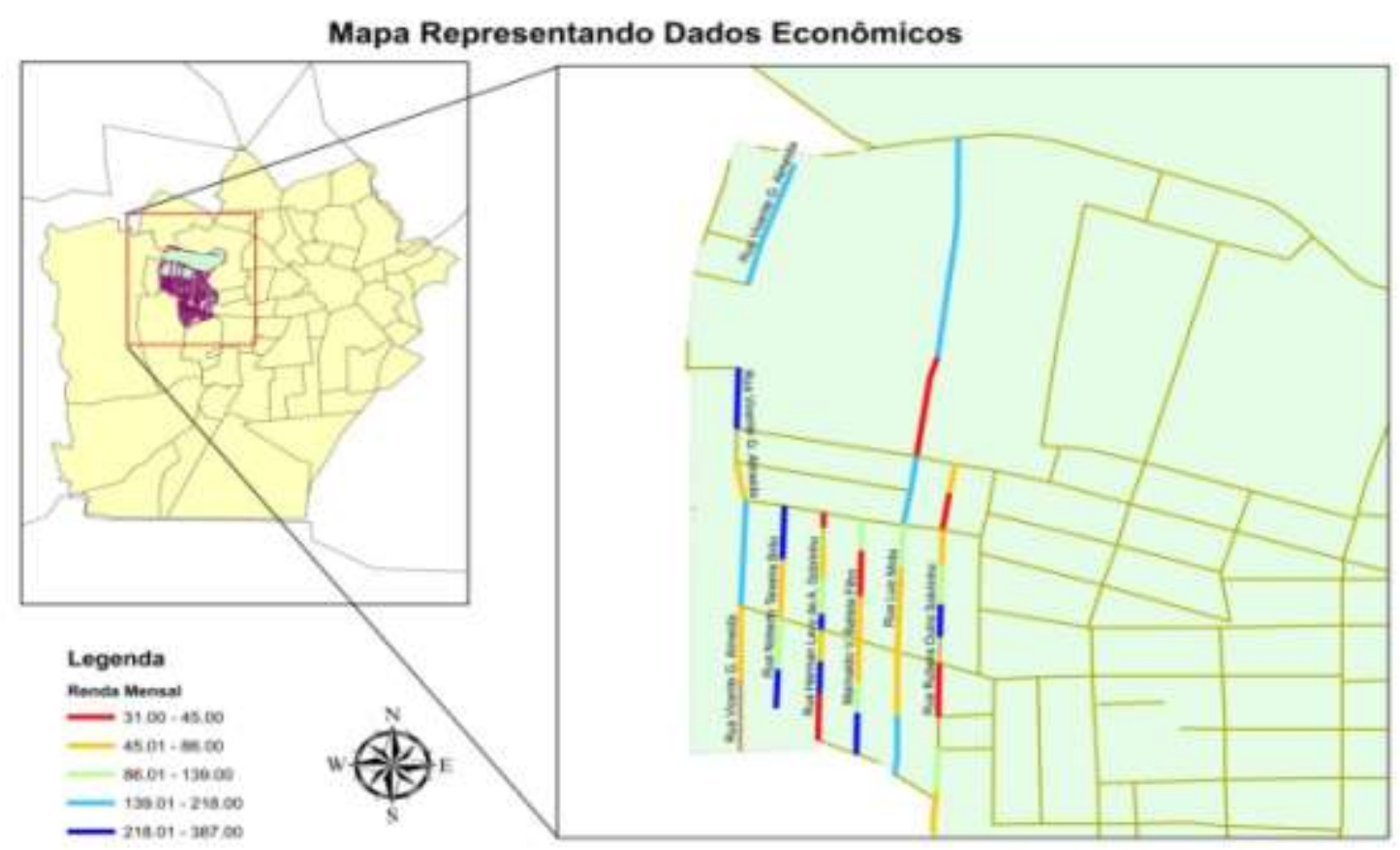

Devido a carência de muitas famílias, mais da metade da população usufruí do programa social Bolsa Família (Figura 10), embora esta informação possa estar mascarada, pois muitos moradores têm uma renda que não poderia receber este auxilio, e acabam mascarando a informação por medo de perder.

Figura 10 - Ajuda Externa.

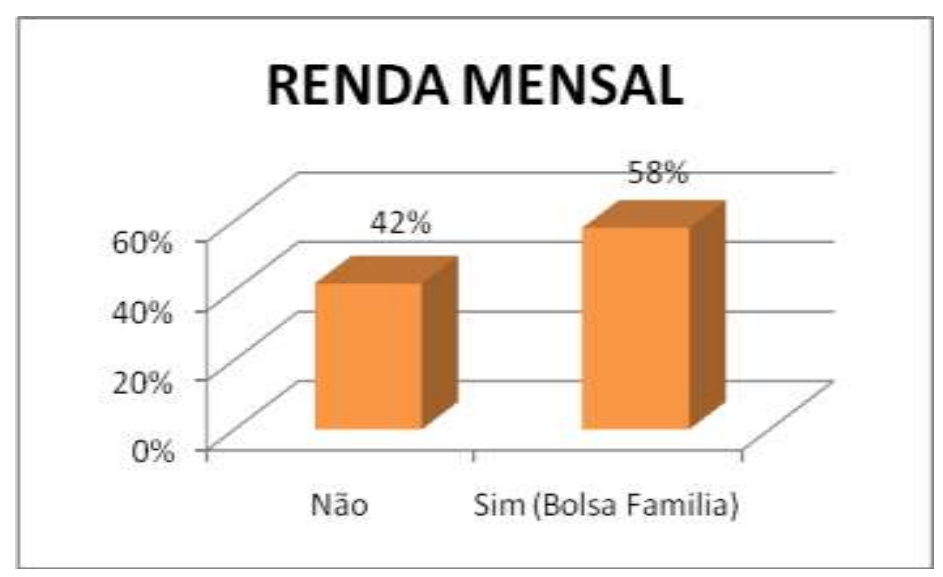

Fonte: Pesquisa de Campo - MEDEIROS, Monalisa Cristina Silva. 2011.

\subsubsection{Moradia}




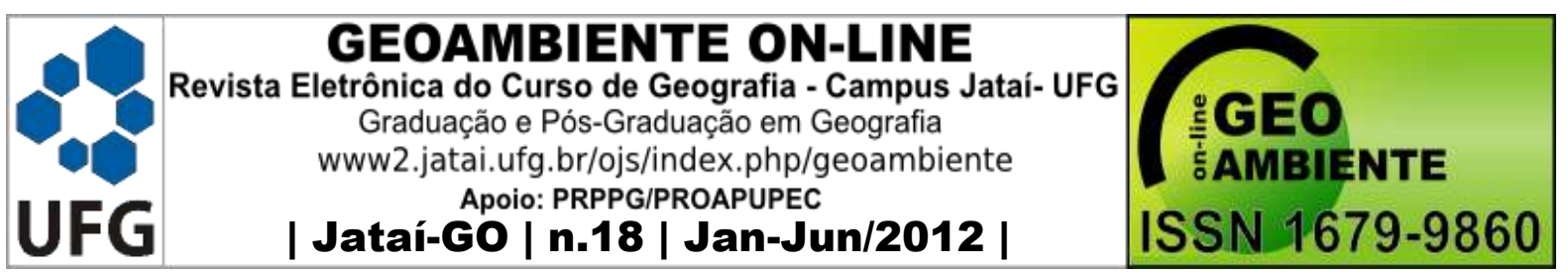

As residências do bairro são de alvenaria, em sua maioria em bom estado (Figuras 11). Foi constatado que $70 \%$ da população as residências são próprias, sobretudo a parcela da população residente há mais de quinze anos.

Figura 11 - Residência.

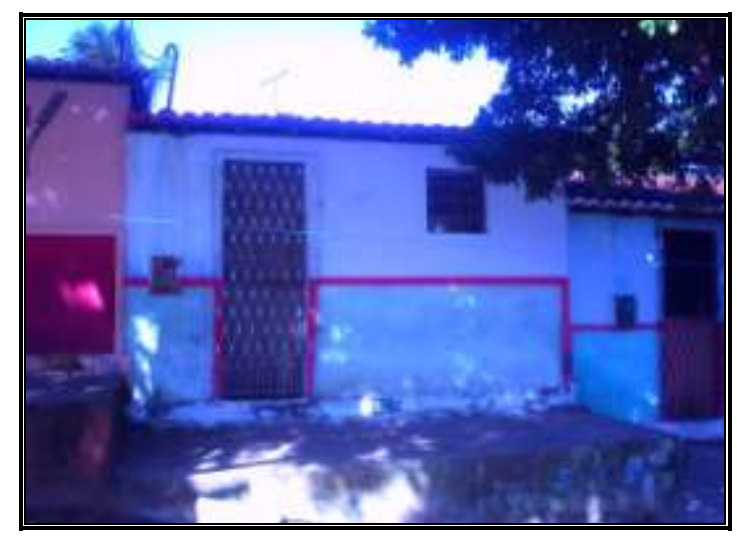

Fonte: Pesquisa de Campo - MEDEIROS, Monalisa Cristina Silva, 2011.

Indagados sobre esta variável, os moradores revelam que a aquisição da casa própria se deu através de financiamentos, algumas ainda em fase de pagamento. Os demais domicílios são alugados ou emprestados por familiares, onde os moradores revelam que a opção de residir ali é devido ao baixo custo financeiro do aluguel, isso porque como o bairro não disponibiliza de uma boa infra estrutura, tais custos tem que ser baixo para poderem ser ocupados.

\subsection{Condições ambientais}

O bairro de Bodocongó possui condições ambientais adversas à população, onde foi identificado vários problemas na infra-estrutura que reflete na qualidade de vida da mesma. Muitos moradores revelam que os problemas existem há anos e persistem sem nenhuma ação por parte dos gestores públicos, a não ser promessas em período eleitoral. Há aqueles ainda que afirmam que não deixam de residir no bairro em virtude do tempo de moradia, enquanto outros que passam a residir, e logo começa a sentir o desconforto causado por estes problemas preferem fixar moradia em outro bairro.

Quando se realiza a Análise Ambiental em qualquer localidade urbana, fatalmente se depara com uma infinidade de problemas ambientais decorrentes de ações antrópicas e na maioria das vezes a falta de planejamento e gestão pública. Strripp \& Strripp (2004 p. 25), afirma que o homem, através de uma ação ou de um empreendimento pode provocar impactos no meio ambiente degradando-o ou destruindo-o, às vezes, de forma irreversível. Atualmente 


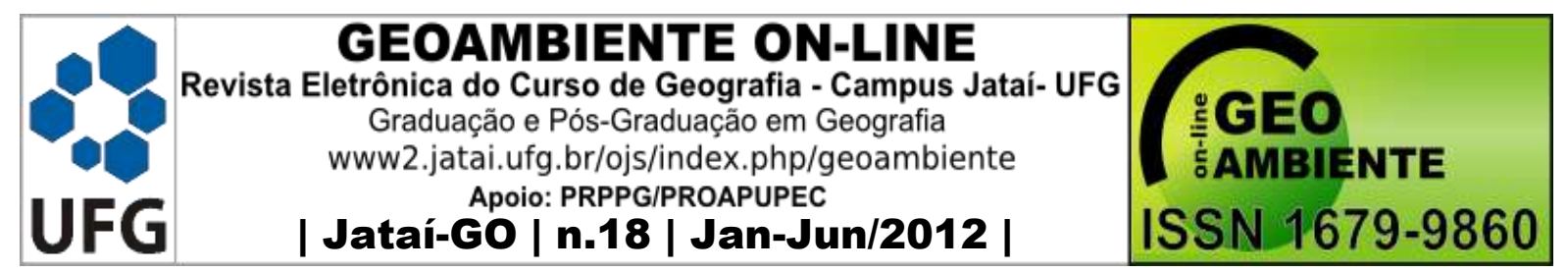

em virtude da ausência de planejamentos nas áreas urbanas, onde os impactos não se restringe ao meio ambiente físico, mas se estende a qualidade de vida da população, como pode ser detectado no bairro de Bodocongó.

O bairro em sua totalidade possui abastecimento de água pela rede de distribuição pública, mas os moradores a partir de sua própria percepção em sua maioria demonstram insatisfação quanto a qualidade da água (Figura 12), onde $60 \%$ considera, regular a sua qualidade. O recorte analisado do bairro ainda possui saneamento básico com algumas deficiências, pois em algumas ruas o esgoto é lançado nas mesmas. Além disso, não existe sistema de drenagem, onde a água da chuva muitas vezes sem ter para onde escoar acaba invadindo algumas casas.

Figura 12 - Qualidade da água.

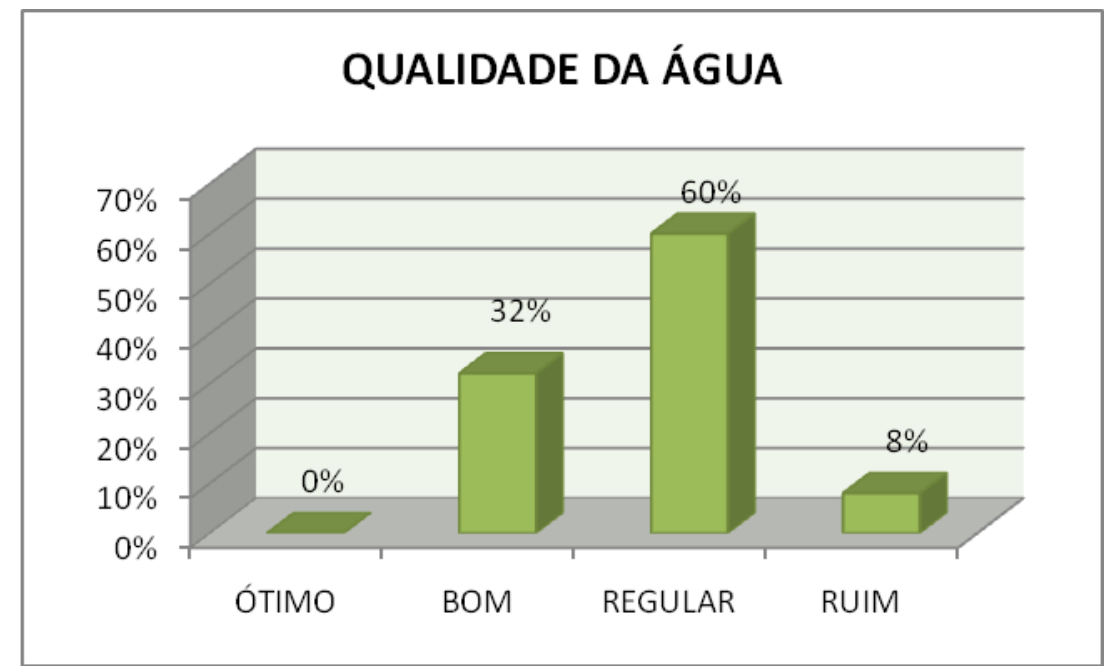

Fonte: Pesquisa de Campo - MEDEIROS, Monalisa Cristina Silva. 2011.

As ruas são pouco arborizadas, revelando uma escassez de áreas verdes, com pouca presença de vegetação. Nas residências em sua maioria não existe vegetação, mas em algumas se destaca as plantas ornamentais e Ficus benjamina (Ficus).

A coleta dos resíduos sólidos é realizada pela Prefeitura Municipal. Apesar de uma coleta regular, o que se verifica é que muitos moradores acabam despejando resíduos em terrenos baldios, provocando danos ao meio ambiente e para própria população local. Isso ocorre devido à ausência de políticas públicas que possibilitem uma conscientização ambiental, o que pode ser constatado ao observamos que não existe nenhum tipo de prática ecológica por parte dos moradores, onde muitos nem ao menos sabem o significado e importância desta atitude, e outros apesar de ter conhecimento, prefere ficar no comodismo, 


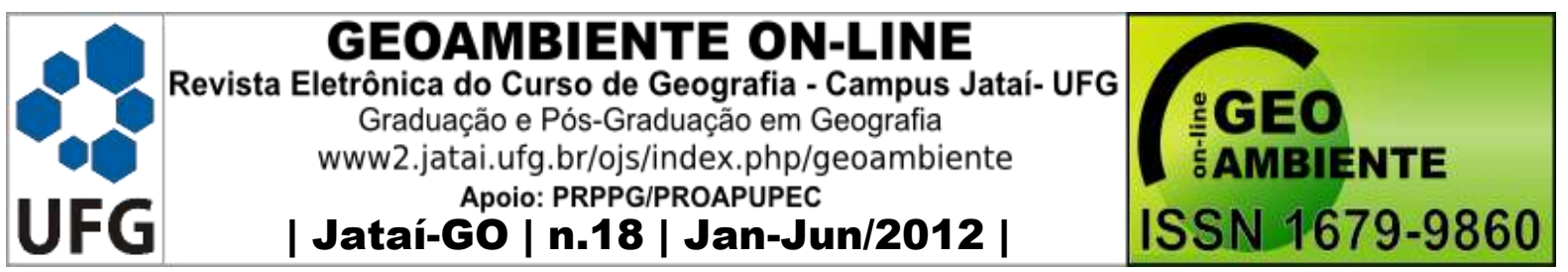

afirmando que o bairro já encontra-se numa situação precária, e sua atitude não teria nenhum resultado.

Neste contexto, é possível identificar os principais problemas enfrentados pelos moradores. Estes problemas ambientais (Figura 13) ocasionam transtornos para população, atrapalhando as atividades humanas da localidade, causadas na maioria das vezes por fatores antrópicos. Sendo assim, foi constatado a problemática dos resíduos sólidos, onde a principal reclamação dos moradores é quanto à proliferação de ratos e moscas que sempre invadem as casas mais próximas aos terrenos, à exalação do mau cheiro, o surgimento de doenças, sobretudo para as crianças que muitas vezes brincam próximo a estes terrenos, quando não chegam a brincar com o próprio lixo, e o transtorno do visual desolador por um local com um amontoado de lixo, resultado da ação dos próprios moradores, que fazem destes locais públicos um depósito de lixo, e embora a prefeitura limpe estes locais a população torna a realizar as mesmas práticas.

Figura 13 - Problemas Ambientais

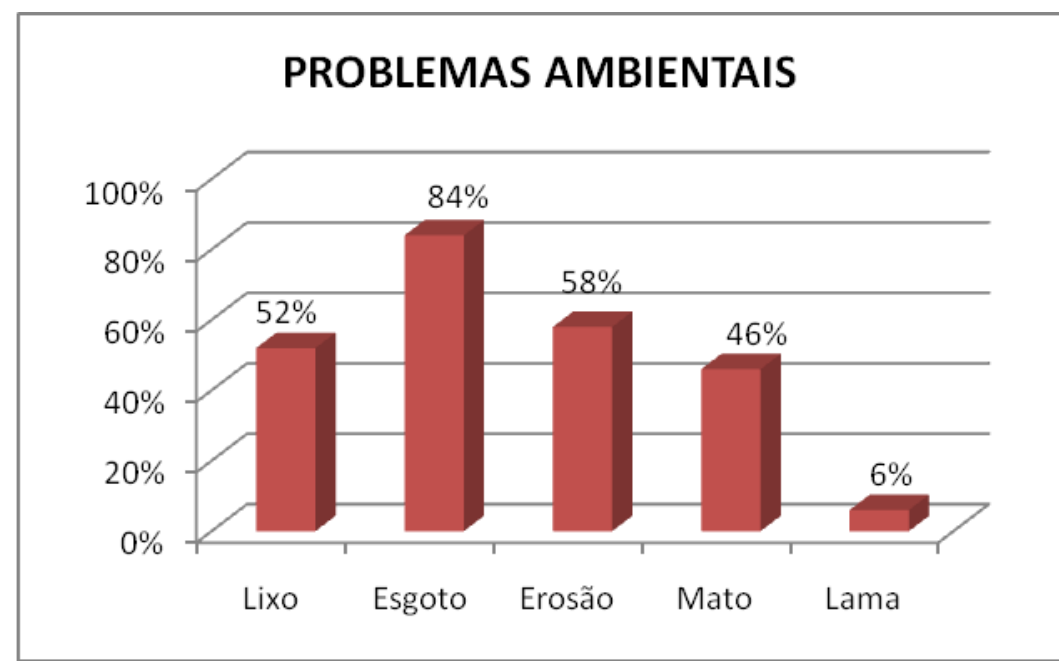

Fonte: Pesquisa de Campo - MEDEIROS, Monalisa Cristina Silva. 2011.

Outro problema enfrentado é com relação ao esgoto (Figura 14), que em virtude de um saneamento básico precário, gera inúmeros corpos d'água pelas ruas, causando um grande desconforto à população que tem que conviver com o mau cheiro, proliferação de roedores, insetos e baratas que invadem as casas, tornando-se assim um transtorno para a comunidade. Este fato leva a origem de enfermidades em algumas crianças que brincam e percorre frequentemente o local e algumas mães relatam que muitas vezes seus filhos foram 


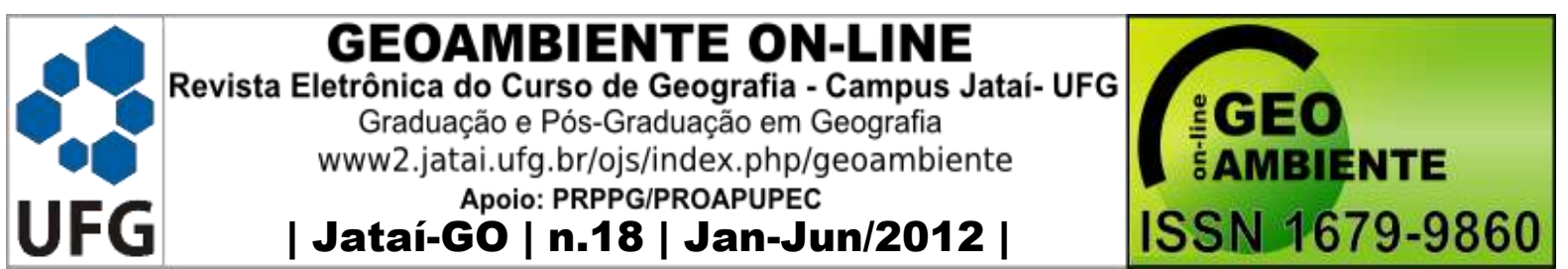

acometidos de enfermidades provenientes de bactérias ou micróbios do esgoto, revelando assim o estreito relacionamento entre a carência de infra-estrutura de saneamento básico e indicadores de saúdes, onde a ausência de um saneamento básico adequado muitas vezes são as principais responsáveis pela proliferação de doenças em determinadas localidade (SILVA, TRAVASSOS, 2008 p. 38).

Figura 14 - Esgoto a céu aberto e acúmulo de lixo.

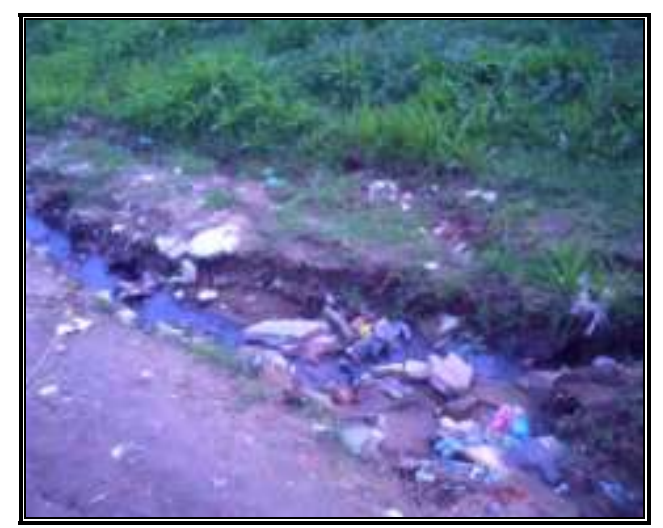

A erosão (Figura 15) é outro problema bastante freqüente, os moradores reclamam dos buracos que atrapalha a passagem de veículos, que em alguns trechos de algumas ruas esta passagem fica totalmente impossibilitada, além dos próprios moradores que muitas vezes tem dificuldade para se locomoverem. Isso ocorre devido a ausência de planejamento, pois como ressalta Silva, Travassos (2008):

A partir da justaposição de diferentes projetos de loteamento, geralmente definidos sobre modelos idealizados de projetos de loteamento, a malha urbana vai se estruturando sem considerar a topografia, a declividade e o sistema de drenagem do sitio real, implicando declividades inadequadas, remoção do solo superficial e exposição do solo de alteração p. 41.

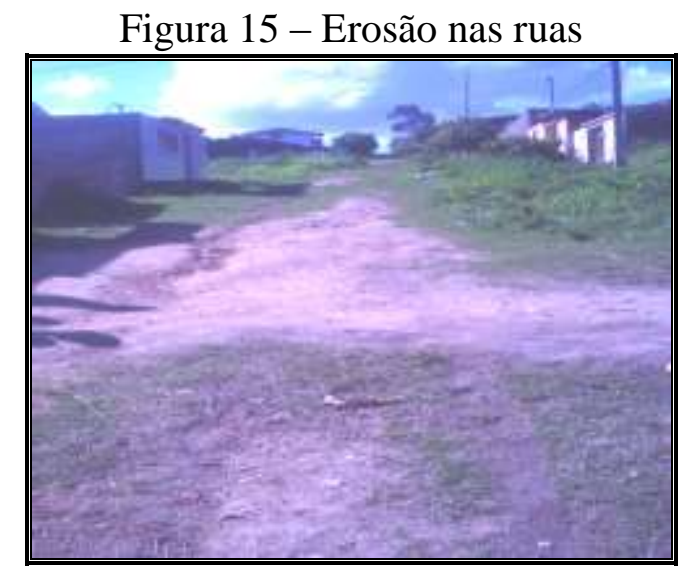

Fonte: Pesquisa de Campo MEDEIROS, Monalisa Cristina Silva, 2011. 


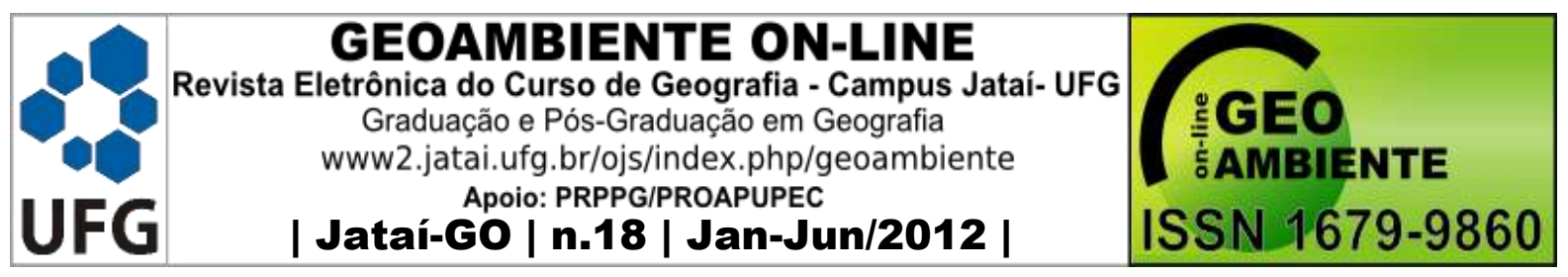

O mato e lama (Figuras 16 e 17) são outros fatos constantes no cotidiano dos moradores, que sofrem, sobretudo no período chuvoso, resultando em pequenos acidentes, onde moradores relatam que é comum pessoas deslizarem e ter alguma parte do corpo fraturada, ou até mesmo motos, causando algumas vezes sérios danos aos moradores. $\mathrm{O}$ mato, juntamente com a lama e o lixo em alguns pontos evidencia, portanto o descaso dos gestores públicos e medidas urgentes de planejamento.

Figura 16 - Ruas não calçadas cheias de Figura 17 - A lama é constante nas ruas. arbustos.
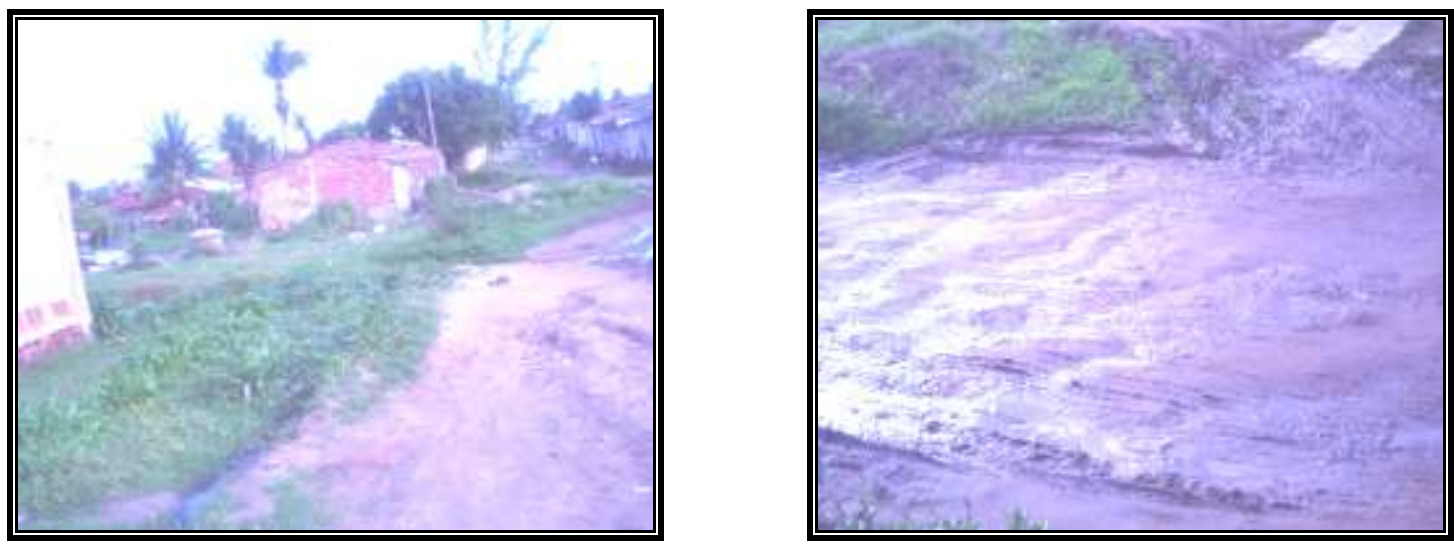

Fonte: Pesquisa de Campo - MEDEIROS, Monalisa Cristina Silva, 2011.

Diante desta situação, os moradores avaliam as condições de moradias do bairro e $70 \%$ afirmam que o mesmo não possibilita uma boa qualidade de vida, com diversos problemas que na maioria das vezes trazem sérios transtornos a população e consideram de ruim a péssima a infra-estrutura do bairro (Figura 18). É comum os moradores ressaltarem que não saem deste local para fixar moradia em outro bairro por falta de condições, mas a insatisfação é visível em todos.

Neste contexto surge a discussão sobre as melhorias na infra-estrutura do bairro, e os moradores elencam alguns indicadores de extrema importância como pode ser observado na figura 19. Como prioridade existe a necessidade da pavimentação das ruas, sendo esta a principal reivindicação dos moradores. A melhoria do esgotamento sanitário também é um ponto importante, em virtude do despejo de esgoto nas ruas, ainda existe a questão da segurança, isso porque, não há presença de policiamento, os assaltos são constantes e os 


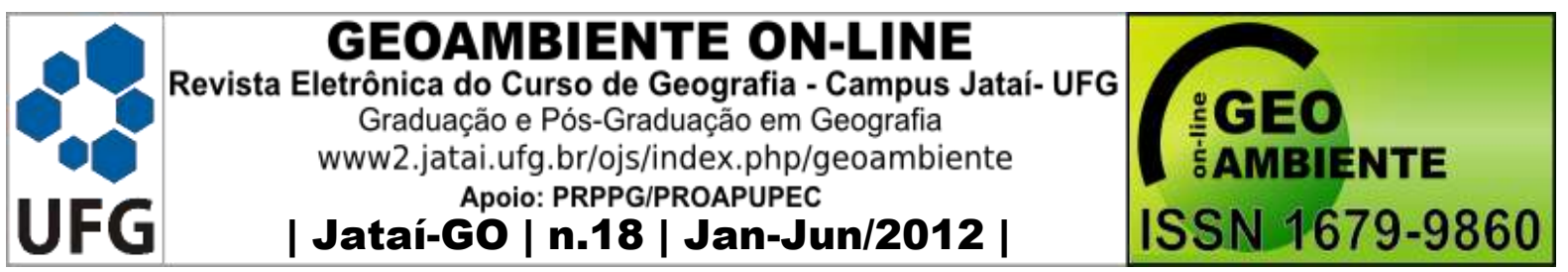

moradores relatam que a noite o medo impede as pessoas de saírem de suas casas, sobretudo em virtude de uma má iluminação, sendo esta outra reivindicação dos mesmos.

Figura 18 - Infra Estrutura do Bairro.

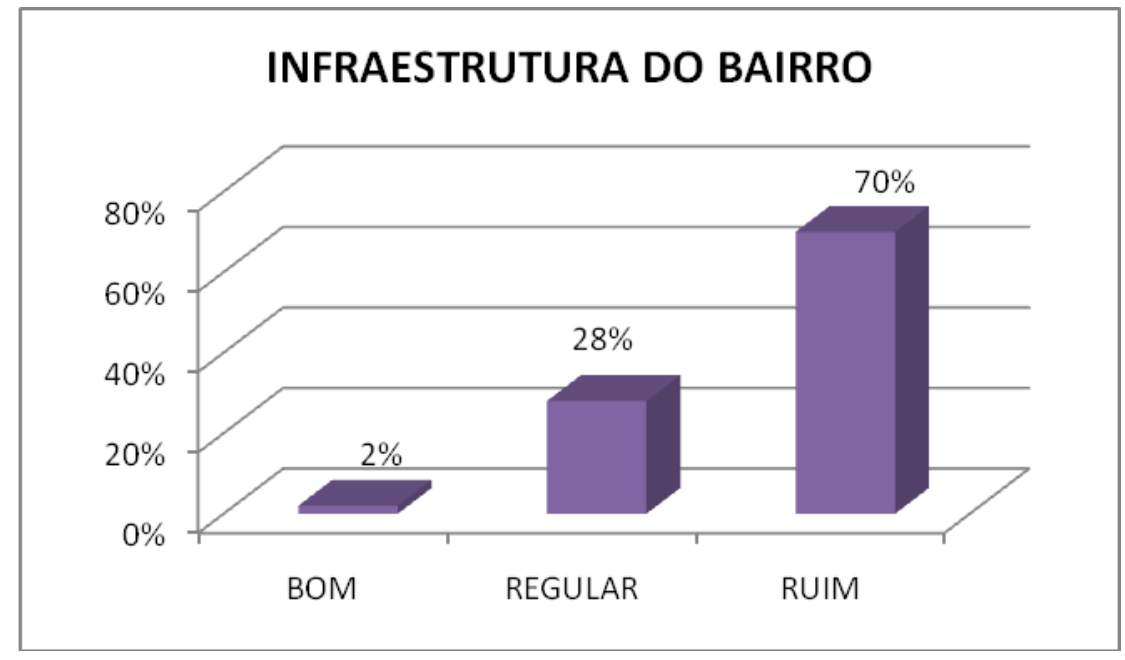

Fonte: Pesquisa de Campo - MEDEIROS, Monalisa Cristina Silva. 2011.

Figura 19 - Sugestões para melhorias no bairro.

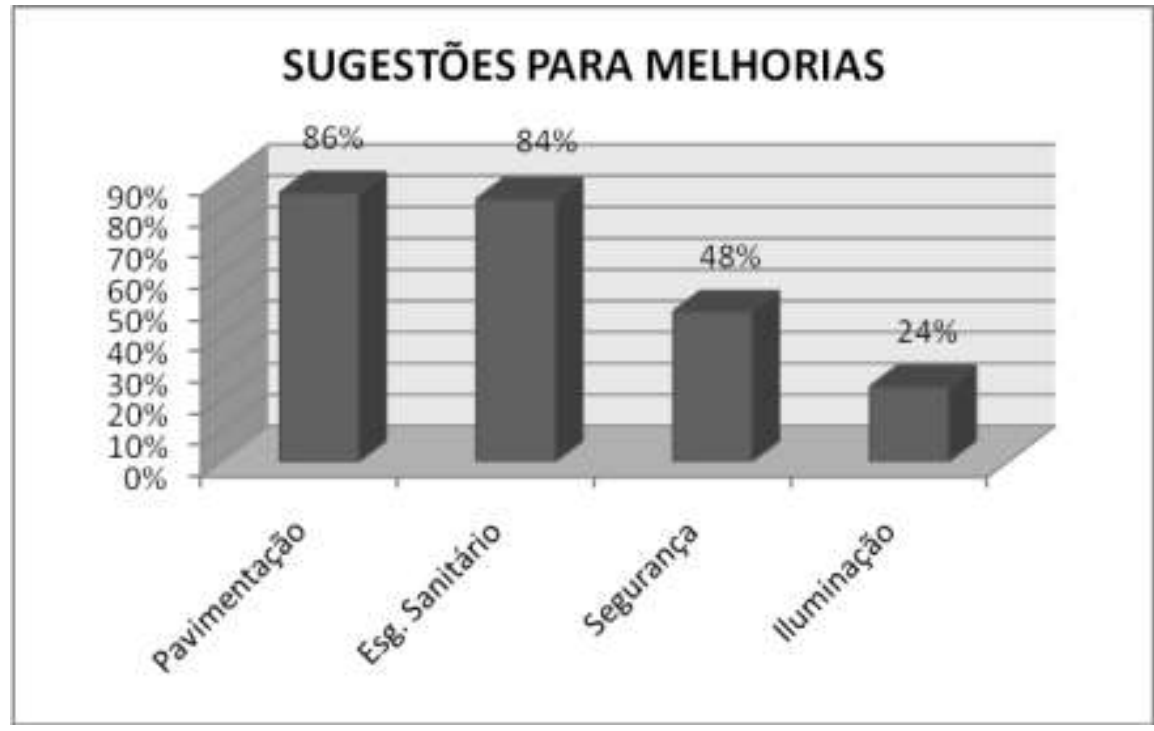

Fonte: Pesquisa de Campo - MEDEIROS, Monalisa Cristina Silva. 2011.

Sendo assim, constata-se que o bairro de Bodocongó é carente de políticas públicas, merecendo uma maior atenção por parte dos gestores públicos com vistas a solucionar os 


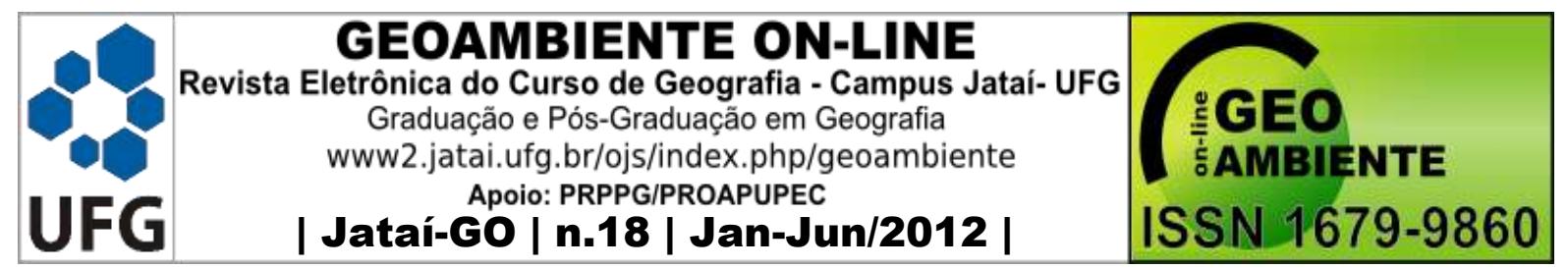

problemas existentes na área através de um planejamento e gestão pública adequados para localidade. De acordo com Souza 2004 apud César (2010) o planejamento consiste em:

\begin{abstract}
buscar, uma prevenção, ou melhor, sem sombra de dúvida conhecer a realidade posta, avaliar os caminhos a serem percorridos e elaborar uma referência para um futuro pretendido. Planejamento também pode ser definido como um processo prático de determinações de um plano de idéias a médio longo prazo, tendo um prognostico dos problemas futuros.
\end{abstract}

A problemática ambiental que vivemos atualmente tem comprometido os recursos naturais das cidades, refletindo precarização da qualidade de vida das populações urbanas, assim também como rurais (SILVA, TRAVASSOS 2008). Diante disso, se faz necessário medidas urgentes por partes dos gestores públicos, através de um planejamento que vise a solução e minimização dos problemas de infra-estrutura e busque a prevenção de outros, tentando assim conciliar a qualidade de vida da população com as melhores alternativas possíveis para os problemas instalados no bairro.

O diagnóstico ambiental do bairro fornece subsídios para o ordenamento da ocupação urbana, visando identificar os problemas, apontando assim para as localidades que precisam de maior atenção de uma gestão publica eficaz, de forma a minimizar os prejuízos causados ao meio ambiente, e apontando para melhores condições da própria população, através de propostas do uso e ocupação do solo, com vistas a melhorar as condições de distribuição de infra-estrutura urbana e principalmente habitacionais, conforme afirma Stipp \& Stipp (2004 p.25). Mas isso só será possível se estas medidas forem acompanhadas de programas de educação, conscientização social e ambiental.

Sendo assim, no Bairro de Bodocongó existem áreas extremamente necessitadas de uma maior atenção dos gestores públicos. Diante dos dados obtidos pode-se elencar algumas ações pertinentes à localidade: Melhoria no esgotamento sanitário, maior segurança e iluminação pública, e a Pavimentação, que é a principal reivindicação dos moradores, que resolveria vários problemas como os buracos, lama, depósitos de lixos nas ruas. Sendo estas, medidas que melhorariam consideravelmente as condições ambientais do bairro, de acordo com os próprios moradores. 


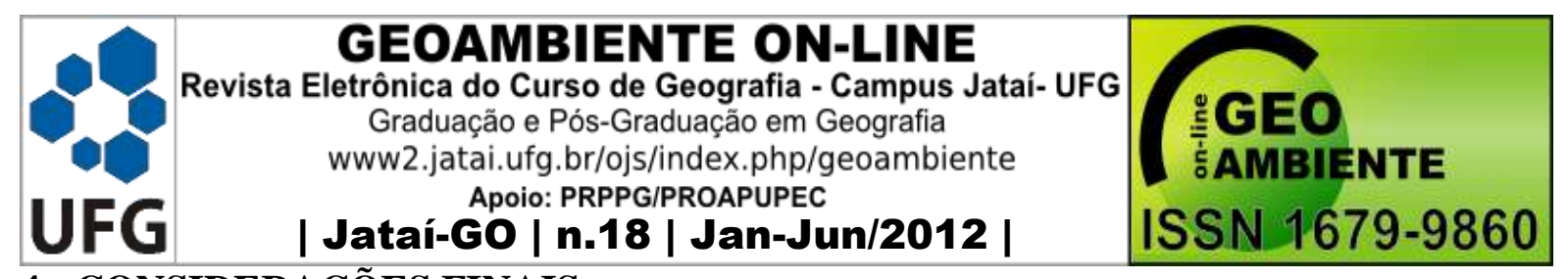

\section{4 - CONSIDERAÇÕES FINAIS}

Com o trabalho realizado neste recorte no bairro de Bodocongó pode-se constatar que com o levantamento realizado foi possível realizar uma analisar o perfil sócio econômico e ambiental, caracterizando o ambiente e sua população.

Como aguisa de conclusão, destaca-se a percepção da população quanto aos problemas enfrentados pela comunidade, e é neste contexto que pode-se evidenciar a importância de técnicas do geoprocessamento e geoestatitica para análises de áreas urbanas com o objetivo de detectar os problemas existentes, e de posse destas informações traçar o perfil da comunidade em seus aspectos sociais e ambientais para então identificar as áreas e as ações mais pertinentes de acordo com as necessidades da população. Desta forma, tais instrumentos consistem em ferramentas de grande importância para a gestão do território, tendo em vista que permite a reprodução da configuração do território identificando vários pontos específicos, permitindo assim um planejamento urbano mais eficaz.

Atualmente muitos problemas são detectados nos espaços urbanos que atinge desde a população ao meio ambiente, como verificou-se no recorte do bairro de Bodocongó, e neste sentido o uso de técnicas de geoprocessamento e geoestatisca é de extrema importância, pois ajuda a identificar os problemas de uma localidade, de maneira que os gestores de posse destas informações terão um melhor e mais seguro embasamento para intervir e investir de acordo com as reais necessidades de cada local, pois para combater os mais diversos problemas urbanos é preciso conhecê-los, saber onde estão para então buscar soluções, assim também como a prevenção.

De posse deste conhecimento, com auxilio das geotecnologias fica mais fácil a gestão urbana, pois com a criação de um banco de dados pode-se identificar as áreas mais precárias de cada localidade de modo a identificar um público-alvo de políticas públicas, que permite o planejamento de acordo com a realidade de cada espaço.

A partir das análises realizadas pode-se compreender e avaliar, que o bairro de Bodocongó necessita de um planejamento urgente que vise os problemas na infra - estrutura, que há anos persistem sem nenhuma ação por parte dos gestores públicos. Apesar da existência de um plano diretor que é um instrumento básico de orientação para uma atuação mais efetiva da administração pública e que visa tais questões, mas infelizmente isso só ocorre na teoria, pois na prática, evidencia-se a ausência de políticas publicas no tocante a uma infraestrutura adequada como pavimentação, saneamento básico, iluminação. E este tipo de 


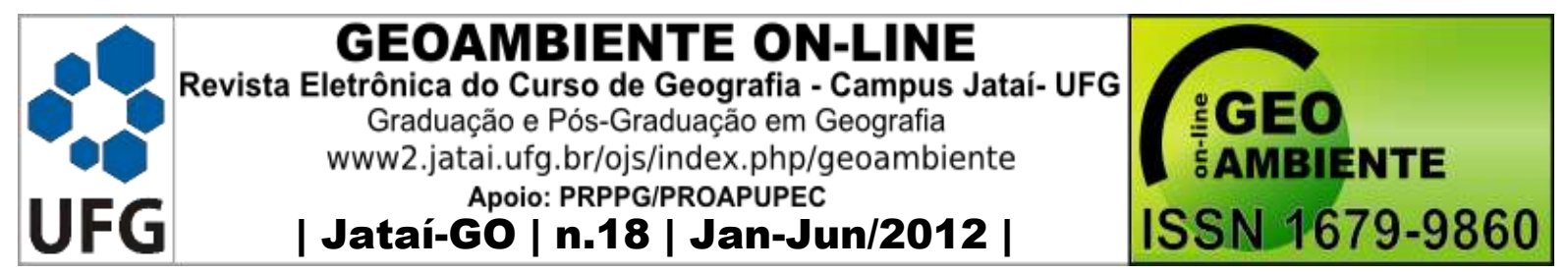

trabalho permite além da identificação dos mais diversos problemas, a partir da analise propor subsídios para um melhor planejamento.

\section{5 - REFERÊNCIAS}

ALMEIDA, Claudia Maria de. O Dialogo entre as Dimensões Real e Virtual do Urbano. In: ALMEIDA, Claudia Maria de; CÂMARA Antonio Miguel; MONTEIRO, Antonio Miguel V. (orgs). Geoinformação em urbanismo: cidade real x cidade virtual. São Paulo. Oficna de Textos, 2007.

ALVES, Edgard Luiz Gutierrez, SOARES, Fábio Veras. Ocupação e Escolaridade: Tendências Recentes na Grande São Paulo. Instituto de Pesquisa Econômica Aplicada. Ministério de planejamento e orçamento. Brasília, 1996. Disponível em:

http://getinternet,.ipea.gov.br. Acesso em: 26 de Outubro, 2010.

ARAÚJO, Jair Barbosa. O algodão de Campina Grande: uma discussão acerca dos livros didáticos de historia. Campina Grande, Agenda, 2006.

BARRETO, Luciano Vieira et al. Análise ambiental e social do bairro São Domingos em Ilhéus - Bahia. Centro Cientifico Conhecer; Goiânia; Enciclopédia Biosfera N.06; 2008; ISSN 1809-05835.

CÂMARA Antonio Miguel; MONTEIRO, Antonio Miguel V. (orgs). Geoinformação em urbanismo: cidade real x cidade virtual. São Paulo. Oficna de Textos, 2007.

CÂMARA, Gilberto; MONTEIRO, Antonio Miguel Vieira; RAMOS, Frederico Romam. Territórios Digitais Urbanos. In: ALMEIDA, Claudia Maria de; CÂMARA Antonio Miguel; MONTEIRO, Antonio Miguel V. (orgs). Geoinformação em urbanismo: cidade real x cidade virtual. São Paulo. Oficna de Textos, 2007.

CAPÍTULO 1 - Introdução ao SIG e Modelagem de Dados. Curso - GIS Introdução.

Disponíbel em: www.epamig.br/geosolos/Apostila_PDF/Geo_cap1.pdf. Acesso em 05 e abril, 2010

CASTRO, Cássio Marcelo Silva. Analise da utilização do Geoprocessamento na administração Municipal: Alcance e limitações dos programas governamentais $e$ disseminação das Geotecnologias. 2009. Dissertação (Mestrado em Engenharia Ambiental Urbana) Universidade Federal da Bahia. Salvador. 


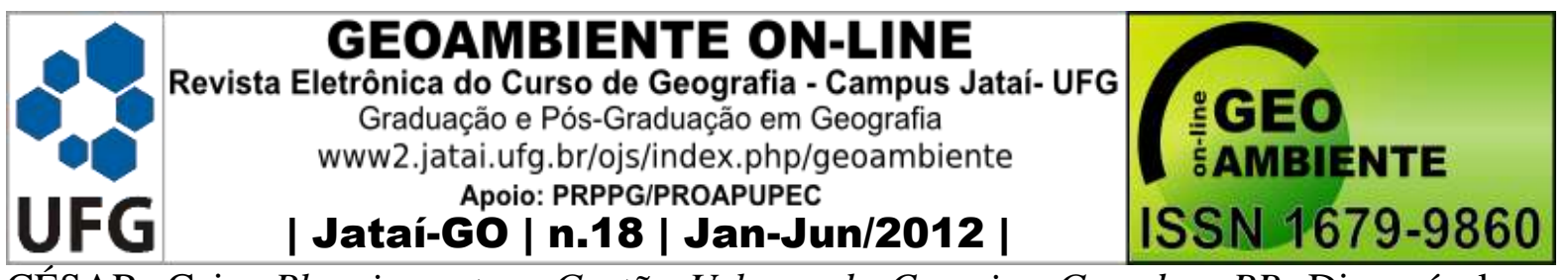

CÉSAR, Caio. Planejamento e Gestão Urbana de Campina Grande - PB. Disponível em: http://www.webartigos.com/articles/46244/1/Planejamento-e-Gestao-Urbana-de-Campina-

Grande---PB/pagina1.html\#ixzz12s8zPupL.

CORDOVEZ, J.C.G. Geoprocessamento como Ferramenta de Gestão Urbana. Anais do I Simpósio e Sensoriamento Remoto. Aracajú/SE, 2002.

CORRÊA, R. L. Construindo o conceito de Cidade Média. In: SPOSITO, M. E. B. Cidades Médias: espaços em transição. São Paulo: Expressão Popular, 2007.

COSTA, Ana Cristina. Geoestatística: Motivação e Conceitos Básicos. Universidade Federal de Pernambuco. 2009.

Disponível em:

http://www.ufpe.br/cgtg/Costa_Geostatistics_UFPE.pdf. Acesso em 06 de abril, 2012.

COSTA, Marcello Alvez; FANTIN, Marcel; MONTEIRO, Antonio MIguell Vieira. A relevância de uma Infra-estrutura Geoinformacional como Subsídio ao Desenvolvimento de Políticas Publicas. In: ALMEIDA, Claudia Maria de; CÂMARA Antonio Miguel;

COSTA, Marilene Bizerra da; VIDAL, Mauricelia Bezerra; CAMELO, Marjony Barros. Processo de implantação do orçamento participativo em Campina Grande - PB. VEREDAS FAVIP, Caruaru, Vol. 2, no 2, jul./dez. 2005 - Vol. 3, ns. 1 e 2, p. 36-46, jan./dez. 2006.

COSTA, Nadja Maria Castilha da; SILVA, Jorge Xavier da. Geoprocessamento aplicado à criação de plano de manejo; o caso do Parque Estadual da Pedra Branca - RJ. In: SILVA, Jorge Xavier; ZAIDAN, Ricardo Tavares. (orgs). Geoprocessamento e Análise Ambiental aplicações. Rio de Janeiro. Bertand Brasil, 2004.

DINIZ, Lincoln da Silva; CASTILHO, Cláudio Jorge Moura de. Faces atuais do espaço comercial em Campina Grande/PB: algumas considerações sobre a Coexistência de formas modernas e tradicionais do comércio na "nova" dinâmica sócio-espacial. Revista de Geografia. Recife: UFPE DCG/NAPA, v. 26, n² 2, mai/ago. 2009.

DOMINGUES, Cristiane Vaz. Aplicação de Geoprocessamento no Processo de Modernização da Gestão Municipal. Resumo de Dissertações e Tese. Informática Pública vol. 8 (2): 109-110, 2007. Disponível em: www.ip.pbh.gov.br/ANO8_N2_PDF/resumocristiane.pdf. Acesso em: 24 de Maio de 2010.

FITZ, Paulo Roberto. Geoprocessamento sem complicação. Oficina de Textos. São Paulo, 2008.

GOMES, Marcos Antonio Silvestre; SUPERBI, Daniel Henrique Almeida; ROSA, Roberto. Aplicações do Geoprocessamento em Estudos Urbanos: Ultilização do Software Arcviem no 


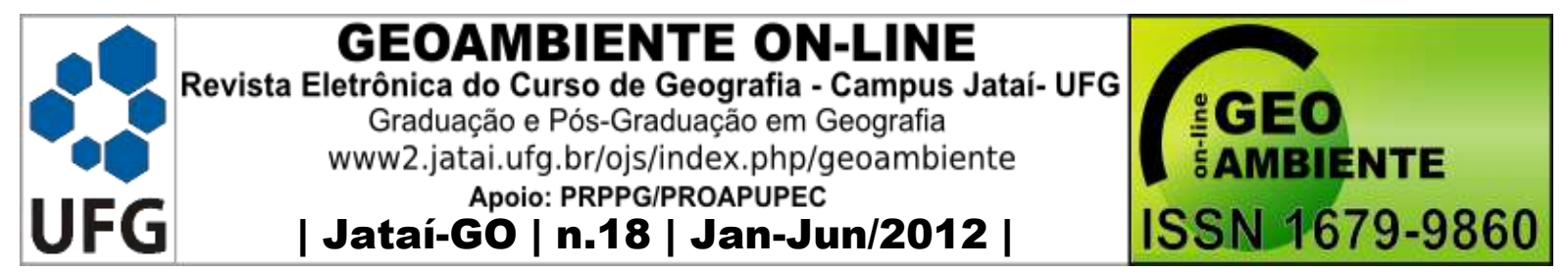

mapeamento de praças publicas em presidente prudente/SP. III Simpósio de Geografia "Perspectiva para o cerrado no século XXI". Universidade Federal de Uberlândia - Instituto de Geografia, 2008.

GOMES, Marisa Prado; AGUIAR, Marcelo Cabral; FERREIRA, Manuel Eduardo. Fundamentos de Geoprocessamento. Universidade Federal de Goiás. Treinamento SEMARH/SIAD. 2005. Disponível em: http://h200137221230.ufg.br. Acesso em: 20 de abril de 2010 .

IBGE. Disponível em:

http://www.ige.gov.br/cidadesat/comparamun/compara.php?codmun=250400\&coduf=25\&te ma=amostra\&amostra\&codv=voi\&long. Acesso em: 20 de junho. 2010.

LEITE, Marcos Esdras; ROSA, Roberto. Geografia e Geotecnologias no estudo urbano. Caminhos da Geografia 17(17) 180 - 186, fev/2006. Instituto de Geografia UFU. Programa de Pós-graduação em Geografia. ISSN 1678-6343.

MEDEIROS, Eveline as Silva. Bodocongó: Águas que queimam Campina Grande, 19171967. Trabalho de conclusão de curso (Monografia) Universidade Estadual da Paraíba, Campina Grande, 2010.

MONTEIRO, Antonio Miguel V. (orgs). Geoinformação em urbanismo: cidade real x cidade virtual. São Paulo. Oficna de Textos, 2007.

Prefeitura Cidade de Campina Grande - SAD/DTI. Campina Grande. Disponível em: http://www.pmcg.pb.gov.br/cidade/htm. Acesso em: 21 de setembro de 2010.

SANTOS, Milton. Por uma Geografia Nova. São Paulo: Edusp, 2002.

SHURCH, Mara Ione Sarturi.. Arborização Urbana: uma contribuição à qualidade de vida com uso de Geotecnologias. 2006. Dissertação (Programa de Pós-Graduação em Geomática) Universidade Federal de Santa Maria. RS. Brasil.

SILVA, Lucia Sousa, TRAVASSOS, Luciana. Problemas ambientais urbanos.

STIPP, Nilza Aparecida Freres; STIPP, Marcelo Eduardo Freres. Análise ambiental em cidades de pequeno e médio porte. Geografia - volume 13 - número 2 - jul/dez. 2004.Disponível em http://www.geo.uel.br/revista. Acesso em 25 de Outubro de 20010.

VEIGA, Teresa Cristina; SILVA, Jorge Xavier. Geoprocessamento aplicadoá identificação de áreas potenciais para atividades turísticas: O caso do município de Macaé - RJ. In: SILVA, Jorge Xavier; ZAIDAN, Ricardo Tavares. (orgs). Geoprocessamento e Análise Ambiental aplicações. Rio de Janeiro. Bertand Brasil, 2004. 